\title{
Two-phase and two-dimensional model describing heat and water transfer during solid-state fermentation within a packed-bed bioreactor
}

\author{
Fernanda Perpétua Casciatori ${ }^{\mathrm{a}, *}$, Andreas Bück $^{\mathrm{c}}$, João Cláudio Thoméo ${ }^{\mathrm{b}}$, Evangelos Tsotsas ${ }^{\mathrm{c}}$ \\ ${ }^{a}$ Center of Natural Sciences, Federal University of São Carlos (UFSCar), Rodovia Lauri Simões de Barros km 12 (SP-189), $18290-000$ Buri-SP, Brazil \\ ${ }^{\mathrm{b}}$ Food Engineering and Technology Department, Institute of Biosciences, Letters and Exact Sciences, São Paulo State University (UNESP), Cristóvão Colombo 2265, \\ Jardim Nazareth, 15054-000 São José do Rio Preto-SP, Brazil \\ ${ }^{\mathrm{c}}$ Thermal Process Engineering/NaWiTec, Otto-von-Guericke University, Universitätsplatz 2, 39106 Magdeburg, Germany
}

\section{H I G H L I G H T S}

- We proposed novel two-phase and two-dimensional model for solidstate fermentation.

- Heat and water transfers are modeled and simulated in packed-bed bioreactor.

- Most transport mechanisms are included and realistic parameters are applied.

- Model predictions agreed with experimental data concerning overheating and drying.

- The novel model can guide the scaleup of bioreactors for solid-state fermentation.

\section{A R T I C L E I N F O}

\section{Article history:}

Received 22 June 2015

Received in revised form 9 October 2015

Accepted 27 October 2015

Available online 7 November 2015

\section{Keywords:}

Modeling and simulation

Fermentation

Bioreactor

Enzymes

Bioethanol

\section{GR A P H I C A L A B S T R A C T}

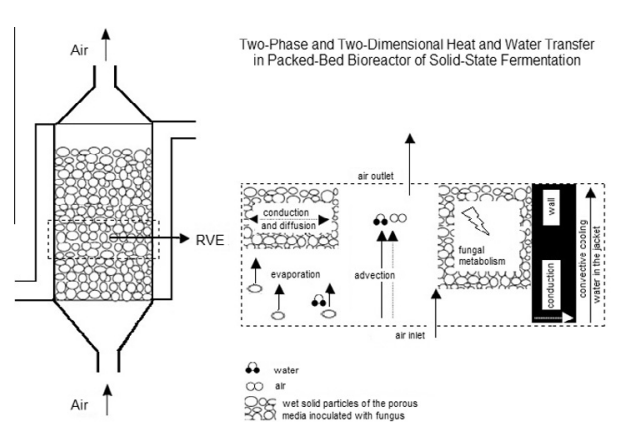

\begin{abstract}
A B S T R A C T
In the current paper, a two-phase and two-dimensional model describing heat and water transfer in a packed-bed bioreactor (PBB) for solid-state fermentation (SSF) is proposed. The model considers most of the transport mechanisms taking place in solid and gas phases and for axial and radial directions. For simulation, realistic physical properties of the particles and of the bed were employed, as well as interface coefficients were calculated based on classical correlations. The case-study was the solidstate cultivation of the newly isolated thermophilic fungus Myceliophthora thermophila I-1D3b in a mixture of sugarcane bagasse (SCB) and wheat bran (WB) within a narrow cylindrical and jacketed PBB. For non-saturated aeration, results showed that substrate drying near the inlet of the bioreactor harms fungal growth. For narrow PBB, jacket plays important rule on heat removal; for large-diameter PBB, radial heat removal becomes negligible. Simulated results agreed with experimental ones. The novel model here proposed is a powerful tool for guiding the scale-up of PBB for SSF.
\end{abstract}

(c) 2015 Elsevier B.V. All rights reserved.

\section{Introduction}

Packed-beds are extensively used in important unity operation in chemical, food and process industries. Some application exam-

\footnotetext{
* Corresponding author. Tel.: +55 (15) 3256 9000; fax: +55 (17) 32212299.

E-mail address: fernandacasciatori@yahoo.com.br (F.P. Casciatori).
}

ples include their use as separators, absorbers, dryers, filters, heat exchangers and chemical and biochemical reactors [1-3]. Solid state fermentation (SSF) bioreactor is a particular case of packed beds, which is under the spotlight in literature.

SSF is a biotechnological process that offers numerous economic and industrial advantages to reduce production costs of fermented products. It concerns the culture of microorganisms on moist solid 
substrates, without dripping water, and a continuous gas-phase in the inter-particle spaces. SSF technology provides new processes opportunities as it allows the use of agro-industrial by-products as substrates without needing an extensive pretreatment, leading to the production of high concentrations of high-added value products, such as enzymes. Moreover, because SSF products are not highly diluted, they can be easier to recover than products produced in traditional submerged fermentation (SbF) $[4,5]$.

A special group of enzymes that has received attention from scientific and technological communities is the group of cellulolytic enzymes. These enzymes are able to depolymerize the biomass of agricultural residues into fermentable sugars through an ecologically friendly route. The final target is producing biofuels from biomass, a sustainable alternative to increase fuel production without decreasing croplands for food production. SSF has been used to produce cellulases, hemicellulases and ligninases from a variety of biomasses, such as green or dried grasses, sugarcane bagasse, wheat bran, rice straw, soybean hulls, sawdust, orange pulp and peel, corncob and corn straw [6-14].

Due to the low water activities, filamentous fungi are the most suitable microorganisms for SSF. Moreover, for the majority of filamentous fungal species, solid-state media reproduce their natural habitat [15]. One extra-advantage in using filamentous fungi in SSF is that such microorganisms have an extraordinary capacity to secrete large amounts of proteins and other metabolic products to the growth medium, so it is feasible to be exploited by the biotechnological industry for the production of industrial enzymes [16]. Moreover, thermophilic fungi are gaining attention from researches in SSF due to the intrinsic thermal stability of the enzymes [17] and because some thermophilic fungi have been recently reported as good producers of cellulolytic enzymes complexes in experiments carried out in glass flasks or in plastic bags $[9,18,19]$.

As well as SbF, SSF requires exploratory studies in flasks scale in order to evaluate the adaptation of the microorganism to the culture media and also if the concentration of the interesting product is commercially feasible. The parameters usually controlled at exploratory assays are composition, moisture content and $\mathrm{pH}$ of the substrate, temperature of cultivation and duration of the process. Independent and interaction effects are evaluated at this scale. After the exploratory studies, it is needed to design and develop a bioreactor which fulfils the process needs. However, it is not recommended that the optimal experimental conditions found in glass flasks tests be immediately transposed to the bioreactors tests, since the dynamic conditions observed in the reactors are quite different [20].

There are two basic configurations for SSF bioreactors: the fixed beds and the moving beds. The latter category is best represented by the rotating drum bioreactor, which is operationally flexible and provides efficient automatic control alternatives. Nevertheless, due to its complex design, high cost, elevated maintenance requirement, and non-adequacy to shear stress sensitive filamentous fungi, this equipment is used only in special processes [20]. The fixed bed is the most commonly applied due to its simple design, reduced cost and low maintenance requirements; it can be subdivided into the tray and the packed-bed bioreactors (PBB). The tray configuration is widely used for fermented food production in Far East countries, while the PBB has been largely explored in bench scale experiments for enzyme production especially by shear sensitive filamentous fungi $[21,22]$.

Even though SSF has been considered a promising technique to produce bioproducts, it has not been successfully established as an industrial alternative due to a variety of factors, resulting in lack of industrial equipment, which depends on engineering developments, including simulation and experimentation. Similarly to chemical reactors, heat and mass transfer play crucial role in determining the performance of SSF processes in PBB [3].

One of the main drawbacks while operating PBB is the deficient removal of the metabolically generated heat, due to the low effective thermal conductivity of the substrate and to the low air flow rates employed, leading to poor options for temperature control and few alternatives for scaling up. High temperatures can achieve levels up to $20^{\circ} \mathrm{C}$ above the ideal fermentation temperature, inhibiting the microorganism growth and affecting the production of metabolites [23-25]. This steep temperature increase is more common for mesophilic fungal strains, and in this case one should expect large variations in microbial growth and productivity.

A second equally important drawback in PPB operation for SSF is the reduction of the moisture content of the solid-phase along the process due to microbiological, physical and chemical issues. Water has many functions in SSF [26], since microorganisms are quite sensitive to the water activity of the fermentation system. Therefore, many studies have been published in literature about the dependence of enzyme production on the water content of the porous media. When the moisture content is insufficient, gas and solute diffusions decrease, and cell metabolism is affected due to either the lack of nutrients or the accumulation of toxic compounds in the vicinity of the cell. Water also solubilizes enzymes, which are fundamental for the whole metabolic system of the cell [27]. However, temperature profiles, and consequently moisture content profiles, are difficult to be avoided in PBB due to end-to-end aeration and the use of convective cooling with unidirectional flow of air. Even if the inlet air is saturated, the axial temperature gradients will change its relative humidity, giving it driving force to remove water from the solid-phase [28].

Heat and mass transfer phenomena in PBB for SSF are simultaneous and both depend somehow on the following factors [29]: (a) microbial biomass development: temperature and water activity required, tolerance to temperature and moisture content changes on the system, specific growth rate, microbial physiology, metabolic heat generation rate; (b) porous media characteristics: presence or absence of inert, particles dimension and shape, medium heterogeneity, bed porosity, moisture content, hygroscopic behavior; (c) equipment dimensions: length, diameter, air distribution inside the bed; (d) operational conditions: air flow rate, temperature and relative humidity of the air and jacket temperature. Some of these factors may be considered constant along fermentative processes, particularly the operational conditions, while some others, such as temperature, moisture content and microbial growth, may undergo dramatic changes that will strongly affect the previews of mathematical models.

In this context, mathematical modeling is an essential tool for guiding the design and operation of bioreactors, providing insights into how the several phenomena within the fermentation system combine to result overall process performance [28]. The aim of SSF bioreactor models is to describe how the performance is affected by the several operating variables that can be manipulated attempting to keep the process under control. For instance, a mathematical model may predict how inlet air flow rate, relative humidity and temperature will affect substrate temperature and water content and also how these environmental variables will affect microbial growth and product formation. Therefore bioreactor models should include the microbial growth kinetic to describe the dependence of growing rate, as well as metabolic heat, on the environmental variables [28].

Some mathematical models have been proposed in literature for heat transfer in SSF packed bed bioreactors [30-34], although some basic information required by the models, concerning the physical properties of the porous matrix and the biological characteristics of the microorganism, are scarce in literature and often 
adapted from one biological system to another without a deep consideration about validity of such approaches.

Saucedo-Castañeda et al. [30] were one of the pioneers in this field applying a general energy balance for heat transfer without considering axial and radial dispersions. Sangsurasak and Mitchell $[31,32]$ improved this original model, considering twodimensional heat transfer in a model suitable to several geometries and operational conditions. Sangsurasak and Mitchell [33] extended their own previous model including a term to describe water evaporation from the porous matrix, which contributes significantly to the overall heat removal, even though such phenomenon results in bed drying [35]. The previous models were pseudo-homogeneous, i.e. they considered that in an elementary representative volume of the system the temperatures and species concentrations were equal for both solid and fluid phases [36]. However, the main deficiency of pseudo-homogeneous models is that they forecast water transfer from solid to the air, but they are not feasible to predict the solid moisture reduction. Only heterogeneous models with at least two-phases, gas and solidphases, can well represent drying phenomena thorough the fermentation due to the air percolation.

Von Meien and Mitchell [37] were the first to suggest a heterogeneous two-phase model in SSF to predict temperature and moisture gradients in an intermittently stirred bioreactor with forced aeration, using the same approach applied for heat and mass transfer during grain drying in deep fixed beds; see for instance [38]. Two-phase models have also been applied by Schutyser et al. [39]. Although two-phase models require the always difficult to obtain fluid-to-particle information to be implemented, these models are more realistic and are the only ones able to represent properly water transfer from solid- to gas-phase. Despite the somewhat complexity of Von Meien and Mitchell [37] and Schutyser et al. [39] models, they are still incomplete, once they are onedimensional and do not consider all the contributions for heat and water transfer phenomena inside the bioreactor, such as thermal and water dispersions in both gas- and solid-phases. Moreover, the interface transfer coefficients and important physical properties, such as sorption isotherms, were obtained from literature and do not necessarily correspond to a real SSF system.

In the current study, a two-phase (heterogeneous) and twodimensional (2-D) model describing heat and water transfer during SSF within a PBB is proposed. The advances in relation to previous models are to include most of the transport mechanisms for both phases and both axial and radial directions, such as vapor diffusion in the gas-phase (with diffusion coefficients for axial and radial directions depending on flow), water diffusion by capillary in the solid-phase (isotropic), heat conduction in the gas-phase (with thermal conductivities for axial and radial directions depending on flow), heat conduction in the solid-phase (isotropic), real drying mechanism taking place in packed-beds and heat and water transfer solid-gas using realistic interface coefficients. The process of solid-state cultivation of the newly isolated fungus Myceliophthora thermophila I-1D3b was simulated using physical properties experimentally obtained for the specific culture media, sugarcane bagasse (SCB) and wheat bran (WB), as well as the microbial growth kinetics.

\section{Experimental setup}

The bioreactor consists of a bed of substrate supported by a perforated plate through which air is continuously blown at fixed flow rate throughout the process. The equipment is operated in batchmode as a fixed packed-bed during the whole fermentation. A diagram of the PBB simulated in the current work is provided on Fig. 1. For detailed information about the bioreactor design and

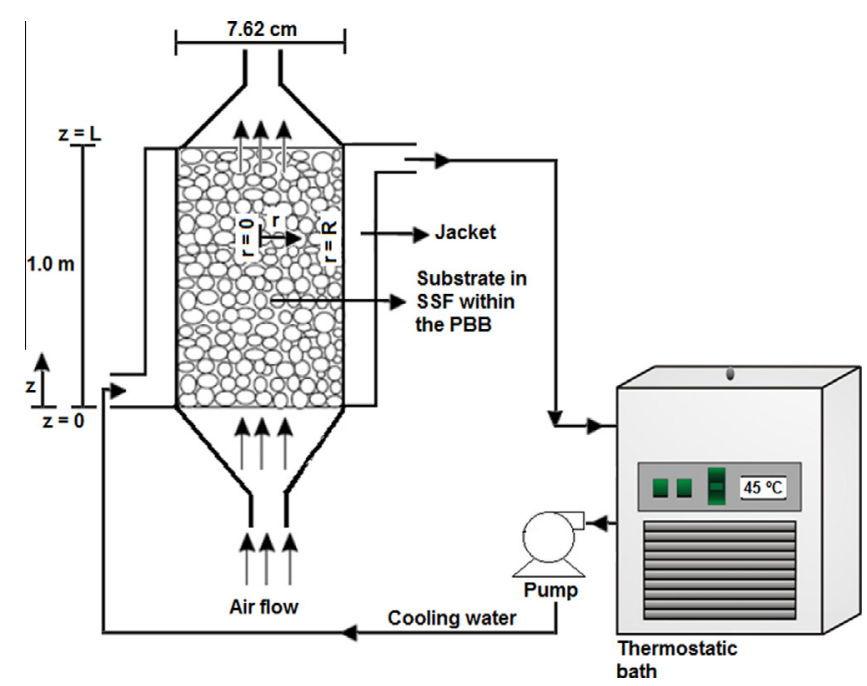

Fig. 1. Schematic diagram of the experimental setup of the PBB for SSF.

experimental operation, see [40]. In the current size $(7.62 \mathrm{~cm}$ diameter; $1.0 \mathrm{~m}$ length), the bioreactor is assumed not wide enough that heat transfer to the walls can be neglected; instead that, jacket plays an important contribution to cooling. Therefore, heat and mass transfers in both axial and radial directions are considered for modeling and simulation.

The microbial system was composed by the newly isolated fungus $M$. thermophila I-1D3b cultivated in a mixture of SCB and WB $(7: 3 \mathrm{w} / \mathrm{w})$. This thermophilic fungus was recently isolated from piles of SCB in an ethanol plant in Olímpia-SP, Brazil, and has already shown to be a very good endoglucanase producer in comparison with other microorganisms in SSF [14]. The porous media was composed by SCB fibers and WB, which average particles sizes are 3 and $0.44 \mathrm{~mm}$, respectively. SCB fibers are the major components, either mass or volume fractions, and fibers were assumed as infinite cylinders with thickness $\left(d_{\text {part }}\right) 0.46 \mathrm{~mm}$ and length ( $\left.L_{\text {part }}\right) 15 \mathrm{~mm}$.

\section{Mathematical modeling}

\subsection{Assumptions}

This paper has focused only in heat and water transfer modeling. Gas transfer was not considered because, in bioreactors with forced aeration, the supply of oxygen to the particle surface was already shown not to be limiting. According to literature, once aeration satisfies cooling requirements, it will also satisfy the need of $\mathrm{O}_{2}$ supply and $\mathrm{CO}_{2}$ removal $[23,30,41]$.

Some assumptions were made to propose and solve the models: thermal and physical properties independent of temperature at the range undergone throughout the fermentation; steady plug-flow air velocity profile; constant bed porosity $\left(\varepsilon_{0}\right)$; mechanism of capillarity for the moisture migration through the solid phase; all quantities well-mixed and total heat and mass transfer area equally distributed within each discrete volume; exothermal and hydrolytic reaction; heat removal by the tube wall; structural and hygroscopic properties of the porous media unaffected by fungal growth; negligible Soret and Dufour effects; particle diameter $\left(d_{\text {part }}\right)$ much smaller than tube diameter.

Table 1 presents the symbols, descriptions and values of the variables, parameters and physical and microbial properties required by the models and used for simulations. 
Table 1

Parameters and variables definitions and values for the nominal case.

\begin{tabular}{|c|c|c|c|}
\hline $\begin{array}{l}\text { Parameter or } \\
\text { variable }\end{array}$ & Description & Value & Source and comments \\
\hline \multicolumn{4}{|c|}{ Independent variables } \\
\hline$t$ & Time & Up to $96 \mathrm{~h} ; t_{0}=0 \mathrm{~s}$ & Chosen based on [14] (nominal \\
\hline$r$ & Radial position & Ranges from 0 to $38.1 \mathrm{~mm}$ & case) \\
\hline$z$ & Axial position & Ranges from 0 to $1 \mathrm{~m}$ & \\
\hline \multicolumn{4}{|c|}{ Dependent variables } \\
\hline Sub & Substrate concentration & Sub $_{0}=98 \mathrm{~kg}$-dry-substrate $/ \mathrm{m}^{3}$ & {$[42]$} \\
\hline$S$ & Total dry solids concentration & $\mathrm{S}_{0}=98.3 \mathrm{~kg}$-total-dry-solids $/ \mathrm{m}^{3}$ & Calculated $\left(S_{0}=B_{0}+\operatorname{Sub}_{0}\right)$ \\
\hline$b$ & Biomass fraction in total dry solids & $b_{0}=0.00281 \mathrm{~kg}$-biomass $/ \mathrm{kg}$-dry-solids & {$[29]$} \\
\hline$B$ & Biomass concentration & $B_{0}=0.3 \mathrm{~kg}$-biomass $/ \mathrm{m}^{3}$ & Calculated $\left(B_{0}=b_{0} \cdot S_{0}\right)$ \\
\hline$T_{g}$ & Temperature of the gas-phase & $T_{g 0}=45^{\circ} \mathrm{C}$ & Chosen based on [14] \\
\hline$T_{s}$ & Temperature of the solid-phase & $T_{s 0}=45^{\circ} \mathrm{C}$ & $T_{s 0}=T_{g 0}$ \\
\hline$Y$ & Water content of the gas-phase & kg-water-vapor/kg-dry-air & $\begin{array}{l}Y_{0} \text { for nominal case of relative } \\
\text { humidity }(\mathrm{RH}) 85 \%\end{array}$ \\
\hline$X$ & Water content of the solid-phase & $X_{0}=3 \mathrm{~kg}$-water $/ \mathrm{kg}$-total-dry-solids & $\begin{array}{l}X_{0} \text { established in substrate } \\
\text { humidification }[14]\end{array}$ \\
\hline \multicolumn{4}{|c|}{ Calculated variables } \\
\hline$Y^{*}$ & Saturation moisture content of the air at $T_{g}$ & kg-water-vapor/kg-dry-air & Calculated by Eq. (A.3a) \\
\hline$a_{w g}$ & Water activity of the gas-phase & Dimensionless & Calculated by Eq. (A.3b) \\
\hline$a_{w s}$ & Water activity of the solid-phase & Dimensionless & Calculated by Eq. (A.4), \\
\hline$\mu_{W}$ & $\begin{array}{l}\text { Fractional specific growth rate on the basis of the } \\
\text { water activity }\end{array}$ & $\begin{array}{l}\text { Dimensionless, Eq. (A.1a), with } D_{1}=131.60 ; D_{2}=94.99 \\
D_{3}=214.22 ; D_{4}=177.67\end{array}$ & $\begin{array}{l}a_{w s}=a_{w g} \text { at equilibrium } \\
{[43]}\end{array}$ \\
\hline$\mu_{T}$ & $\begin{array}{l}\text { Fractional specific growth rate on the basis of the } \\
\text { solid phase temperature }\end{array}$ & Dimensionless, Eq. (A.1b) & [30] \\
\hline$\mu$ & Specific growth rate & $\mathrm{s}^{-1}$, Eq. (A.1c) & {$[44]$} \\
\hline \multicolumn{4}{|c|}{ Design and operating parameters } \\
\hline$a_{w g i}$ & Inlet air water activity & 0.85 (nominal case) -1.00 & Chosen \\
\hline$Y_{\mathrm{i}}$ & Inlet air moisture content & kg-water-vapor/kg-dry-air & Depending on $a_{w g i}$ \\
\hline$v_{0}$ & Inlet air superficial velocity & $0.0146 \mathrm{~m} / \mathrm{s}$ (nominal case) & Chosen based on [14] \\
\hline$T_{g i}$ & Inlet air temperature & $45^{\circ} \mathrm{C}$ & \\
\hline$T_{\text {wall }}$ & Bioreactor wall temperature & $45^{\circ} \mathrm{C}$ & \\
\hline$L$ & Bioreactor total length & $1 \mathrm{~m}$ & Chosen (nominal case) \\
\hline$R$ & Bioreactor total radius & $38.1 \mathrm{~mm}$ & \\
\hline \multicolumn{4}{|c|}{ Gas phase properties } \\
\hline$C p_{a}$ & Dry air heat capacity & $1006 \mathrm{~J} / \mathrm{kg}$-dry-air $/{ }^{\circ} \mathrm{C}$ & {$[45]$} \\
\hline$C p_{v}$ & Water vapor heat capacity & $1880 \mathrm{~J} / \mathrm{kg}$-vapor $/{ }^{\circ} \mathrm{C}$ & \\
\hline$P$ & Plant pressure & $101325 \mathrm{~Pa}$ & \\
\hline$P_{w}{ }^{*}$ & Saturation vapor pressure of water in air & $\mathrm{Pa}$ & {$[46]$} \\
\hline$\rho_{a}$ & Dry air density & $1.11 \mathrm{~kg}$-dry-air $/ \mathrm{m}^{3}$ & [45] \\
\hline $\operatorname{Pr}$ & Prandtl number of the air & $0.71\left(\right.$ at $\left.45^{\circ} \mathrm{C}\right)$ & \\
\hline$v_{a}$ & Kinematics viscosity of the air & $17.5 \times 10^{-6} \mathrm{~m}^{2} / \mathrm{s}$ & \\
\hline \multicolumn{4}{|c|}{ Substrate and bed properties } \\
\hline$C p_{s}$ & Heat capacity of the dry solids & $1760 \mathrm{~J} / \mathrm{kg}$-dry-solids $/{ }^{\circ} \mathrm{C}$ & [47] \\
\hline$C p_{w}$ & Heat capacity of liquid water & $4184 \mathrm{~J} / \mathrm{kg}$-water $/{ }^{\circ} \mathrm{C}$ & [45] \\
\hline$R_{g}$ & Universal gas constant & $8.314 \mathrm{~J} / \mathrm{mol} /{ }^{\circ} \mathrm{C}$ & \\
\hline$\Delta H_{\text {vap }}$ & Enthalpy of evaporation of the water & $2,414,300 \mathrm{~J} / \mathrm{kg}$-water & \\
\hline$\varepsilon_{0}$ & Void fraction or bed porosity (constant) & $0.75 \mathrm{~m}^{3}$-void $/ \mathrm{m}^{3}$-total & {$[42]$} \\
\hline$d_{\text {part }}$ & Substrate particle diameter & $0.45 \mathrm{~mm}$ & Measurements with vernier \\
\hline$L_{\text {part }}$ & Substrate particle length & $1.0 \mathrm{~cm}$ & caliper \\
\hline \multicolumn{4}{|c|}{ Microbial parameters } \\
\hline$A$ & Frequency factor for the numerator Eq. (A.1b) & $7.483 \times 10^{7} \mathrm{~s}^{-1}$ & {$[30]$} \\
\hline$B$ & Fitting constant for the denominator Eq. (A.1b) & $1.300 \times 10^{47}$ & \\
\hline$E_{A 1}$ & Activation energy for the numerator Eq. (A.1b) & $70225 \mathrm{~J} / \mathrm{mol}$ & \\
\hline$E_{A 2}$ & Activation energy for the denominator Eq. (A.1b) & $283356 \mathrm{~J} / \mathrm{mol}$ & \\
\hline $\mathrm{R}_{\mathrm{Q}}$ & Heat yield from growth & $8.366 \times 10^{6} \mathrm{~J} / \mathrm{kg}$-biomass & \\
\hline$R_{W}$ & $\begin{array}{l}\text { Stoichiometric coefficient relating water production } \\
\text { to growth }\end{array}$ & $0.3 \mathrm{~kg}$-water $/ \mathrm{kg}$-biomass & {$[44]$} \\
\hline$R_{S}$ & $\begin{array}{l}\text { Change in total dry solids per kg of fungal biomass } \\
\text { produced }\end{array}$ & -2 kg-total-dry-solids/kg-biomass & [37] \\
\hline$\eta$ & Biomass yield coefficient from substrate & 0.33 kg-biomass/kg-dry-substrate & \\
\hline$b_{\max }$ & $\begin{array}{l}\text { Maximum possible biomass fraction in total dry } \\
\text { solids }\end{array}$ & 0.0327 kg-biomass/kg-total-dry-solids & [29] \\
\hline$\mu_{\mathrm{opt}}$ & Optimum specific growth rate & $1,67 \times 10-5 \mathrm{~s}^{-1}\left(0.06 \mathrm{~h}^{-1}\right)$ & \\
\hline \multicolumn{4}{|c|}{ Transport coefficients and interface transfer coefficients } \\
\hline$\alpha_{\text {wall }}$ & Wall-to-fluid heat transfer coefficient & $\mathrm{W} / \mathrm{m}^{2} /{ }^{\circ} \mathrm{C}$, calculated from Eq. $($ A.5e) & {$[48]$} \\
\hline$D_{s}$ & $\begin{array}{l}\text { Solid-phase effective dispersion coefficient by } \\
\text { capillarity }\end{array}$ & $1.5 \times 10^{-10} \mathrm{~m}^{2} / \mathrm{s}$ & [49] \\
\hline$\lambda_{s}$ & Solid-phase stagnant effective thermal conductivity & $0.065 \mathrm{~W} / \mathrm{m} /{ }^{\circ} \mathrm{C}$ & {$[50]$} \\
\hline \multicolumn{4}{|c|}{ Transport coefficients and interface transfer coefficients } \\
\hline$D_{g, m}$ & Molecular diffusivity of water vapor in the air & $2.5 \times 10^{-5} \mathrm{~m}^{2} / \mathrm{s}$ & {$[45]$} \\
\hline
\end{tabular}


Table 1 (continued)

\begin{tabular}{|c|c|c|c|}
\hline $\begin{array}{l}\text { Parameter or } \\
\text { variable }\end{array}$ & Description & Value & Source and comments \\
\hline$\lambda_{g, m}$ & Molecular thermal conductivity of the air & $0.02745 \mathrm{~W} / \mathrm{m} /{ }^{\circ} \mathrm{C}$ & \\
\hline$D_{g, z}$ & Gas-phase axial effective diffusivity & $\mathrm{m}^{2} / \mathrm{s}$, calculated from Eq. (A.5a) & {$[51,52]$} \\
\hline$D_{g, r}$ & Gas-phase radial effective diffusivity & $\mathrm{m}^{2} / \mathrm{s}$, calculated from Eq. (A.5b) & \\
\hline$\lambda_{g, z}$ & Gas-phase axial effective thermal conductivity & $\mathrm{W} / \mathrm{m} /{ }^{\circ} \mathrm{C}$, calculated from Eq. $(\mathrm{A} .5 \mathrm{c})$ & \\
\hline$\Lambda_{\mathrm{g}, \mathrm{r}}$ & Gas-phase radial effective thermal conductivity & $\mathrm{W} / \mathrm{m} /{ }^{\circ} \mathrm{C}$, calculated from Eq. (A.5d) & \\
\hline$\beta a^{\delta+1}$ & $\begin{array}{l}\text { Volumetric mass transfer coefficient in the interface } \\
\text { solid-gas }\end{array}$ & $\mathrm{s}^{-1}$, see Section A.6 of Appendix A & Proposed in the current work \\
\hline ha & $\begin{array}{l}\text { Volumetric heat transfer coefficient in the interface } \\
\text { solid-gas }\end{array}$ & $\mathrm{W} / \mathrm{m}^{3} /{ }^{\circ} \mathrm{C}$, see Section A.6 of Appendix A & \\
\hline$\dot{v}^{\prime}(X)$ & Modified normalized drying rate & Set equal to 1 (first drying period) & \\
\hline
\end{tabular}

\subsection{Modeling of heat and water transfer}

Both energy and water balances were applied and in both cases individual equations were proposed for the air and the solidphases. Every term in these equations were expressed per cubic meter of bioreactor; thus, terms in the water balance have $\mathrm{kg}$-water $/ \mathrm{m}^{3} / \mathrm{s}$ units, while in the energy balance $\mathrm{W} / \mathrm{m}^{3}$ units.

\subsubsection{Mass balance for water vapor in the gas-phase}

The water balance in the gas-phase was expressed by Eq. (1):

$$
\begin{aligned}
\rho_{a} \varepsilon_{0} \frac{\partial Y}{\partial t}+v_{0} \rho_{a} \frac{\partial Y}{\partial z}= & \dot{v}^{\prime}(X) \beta a \rho_{a} \varepsilon_{0}\left(Y^{*}-Y\right)+\rho_{a} \varepsilon_{0} D_{g, z} \frac{\partial^{2} Y}{\partial z^{2}} \\
& +\rho_{a} \varepsilon_{0} D_{g, r} \frac{1}{r} \frac{\partial}{\partial r}\left(r \frac{\partial Y}{\partial r}\right)
\end{aligned}
$$

The first term on the left-hand side represents the change in water content of the gas-phase, while the second term represents the flow of water vapor in the air stream by advection.

The first term on the right-hand side represents the solid-to-gas interface water transfer, given by the product of the mass transfer coefficient $(\beta)$ and the difference between the true moisture content of the gas-phase $(Y)$ and the saturation moisture content of the air $\left(Y^{*}\right)$, multiplied by $\left(\rho_{a} \varepsilon_{0}\right)$ to fit the units and by the transfer area in a specified volumetric element (a) to give the volumetric rate. This term was also corrected by the modified normalized drying rate $\dot{v}^{\prime}(X)$, which is an empirical drying parameter that accounts for mass transfer resistance in the solid. Considering that the initial water content of the solid matrix was large enough to assure that the solid moisture content would be higher than the critical value $\left(X_{\text {crit }}\right)$ in the bioreactor along the fermentation, the drying was assumed to be undergone at first period for the whole process. Notice that this term does not assume the gas-phase is always saturated, so that it can be also used for the drying of a packed-bed.

The second and third terms on the right-hand side represent the diffusion of water vapor in the gas phase in the axial and radial directions, respectively.

\subsubsection{Mass balance for water in the solid-phase}

The water balance in the solid-phase was expressed by Eq. (2):

$$
\begin{aligned}
S \frac{\partial X}{\partial t}+X \frac{\partial S}{\partial t}= & -\dot{v}^{\prime}(X) \beta a \rho_{a} \varepsilon_{0}\left(Y^{*}-Y\right)+R_{W}\left[S \frac{\partial b}{\partial t}+b \frac{\partial S}{\partial t}\right]+D_{s} S \\
& \times \frac{\partial^{2} X}{\partial z^{2}}+D_{s} S \frac{1}{r} \frac{\partial}{\partial r}\left(r \frac{\partial X}{\partial r}\right)
\end{aligned}
$$

The first term on the left-hand side represents the change in water content of the solid-phase. Since total dry solids concentration $(S)$ is changing on time simultaneously with moisture content in total dry solids $(X)$, the product rule was used in order to isolate the variable of interest $X$.

On the right-hand side, the first term corresponds to the amount of water being removed from the solid-phase by drying, which is the same amount of water being incorporated to the gas-phase, so that it represents the water transfer in the solid-gas interface. The second term represents the water produced during the fermentation as a consequence of the microbial growth. Therefore, in the same way as for the term on the left-hand side, the product rule had to be used for the metabolic water production term.

The last two terms on the right-hand side in Eq. (2) represent the dispersion of liquid water in axial and radial directions, respectively. It must be pointed out that, in a porous medium, liquid diffusion through the solid phase is dominated by the capillarity mechanism. Therefore, the diffusion coefficient has not the same meaning as the molecular solid diffusion coefficient; see [53] for more details on this assumption.

\subsubsection{Energy balance for the gas-phase}

The energy balance in the gas-phase was expressed by Eq. (3):

$$
\begin{gathered}
\rho_{a} \varepsilon_{0}\left(C p_{a}+Y C p_{v}\right) \frac{\partial T_{g}}{\partial t}+v_{0} \rho_{a}\left(C p_{a}+Y C p_{v}\right) \frac{\partial T_{g}}{\partial z}=\Delta H_{\text {vap }}\left(T_{s}\right) \\
\cdot v^{\prime}(X) \beta a \rho_{a} \varepsilon_{0}\left(Y^{*}-Y\right) \cdots-\mathrm{ha}\left(T_{g}-T_{s}\right)+\varepsilon_{0} \lambda_{g, z} \frac{\partial^{2} T_{g}}{\partial z^{2}} \\
+\varepsilon_{0} \Lambda_{g, r} \frac{1}{r} \frac{\partial}{\partial r}\left(r \frac{\partial T_{g}}{\partial r}\right)
\end{gathered}
$$

The first term on the left-hand side represents the accumulation of energy in the gas-phase along the fermentation. The second term represents the flow of energy with the air stream by advection. In both these terms, the quantity $\left(C p_{a}+Y C p_{v}\right)$ represents the heat capacity of the moist air.

The first term on the right-hand side represents the amount of energy associated to the evaporation flux of water in the interface between the gas- and the solid-phases. The second term on the right-hand side describes the convective heat transfer in the gassolid interface. The last two terms represent the heat conduction through the air in axial and radial directions, respectively.

\subsubsection{Energy balance for the solid-phase}

The energy balance in the solid-phase was expressed by Eq. (4):

$$
\begin{aligned}
& S\left(C p_{s}+X C p_{w}\right) \frac{\partial T_{s}}{\partial t}+T_{s}\left(C p_{s}+X C p_{w}\right) \frac{\partial S}{\partial t}=\operatorname{ha}\left(T_{g}-T_{s}\right) \\
& -\Delta H_{\text {vap }}\left(T_{s}\right) \dot{v}^{\prime}(X) \beta a \rho_{a} \varepsilon_{0}\left(Y^{*}-Y\right) \cdots+R_{Q}\left[S \frac{\partial b}{\partial t}+b \frac{\partial S}{\partial t}\right] \\
& \quad+\left(1-\varepsilon_{0}\right) \lambda s \frac{\partial^{2} T_{s}}{\partial z^{2}}+\left(1-\varepsilon_{0}\right) \lambda_{s} \frac{1}{r} \frac{\partial}{\partial r}\left(r \frac{\partial T_{s}}{\partial r}\right)
\end{aligned}
$$

The term on the left-hand side represents the accumulation of energy in the solid-phase. Since total dry solids concentration $(S)$ is changing on time simultaneously with solid-phase temperature $\left(T_{s}\right)$, the product rule was used within this term in order to isolate the variable of interest $T_{s}$. The quantity $\left(C p_{s}+Y C p_{w}\right)$ represents the heat capacity of the moist solid. It is assumed that heat capacity of the biomass formed is equal to that of the substrate. 


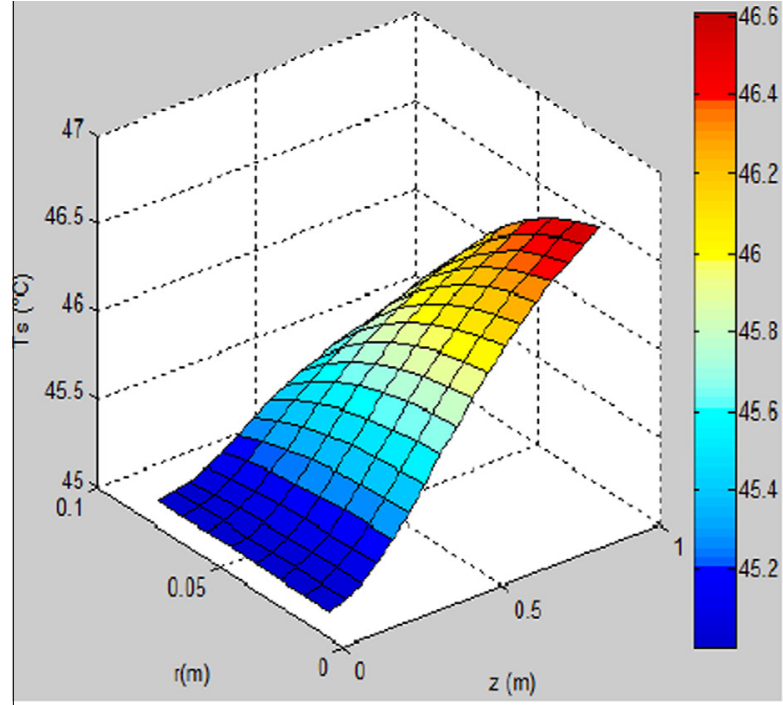

(a)

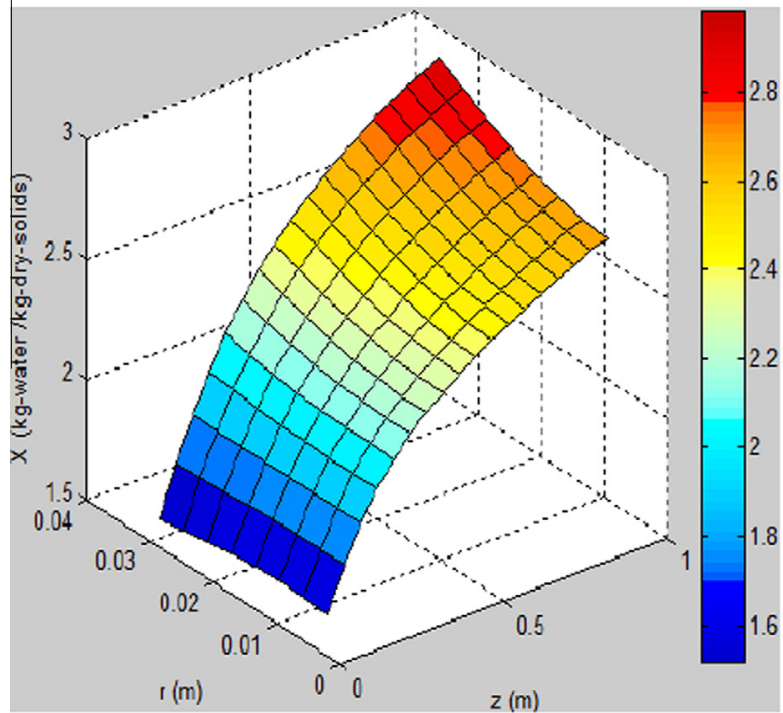

(c)

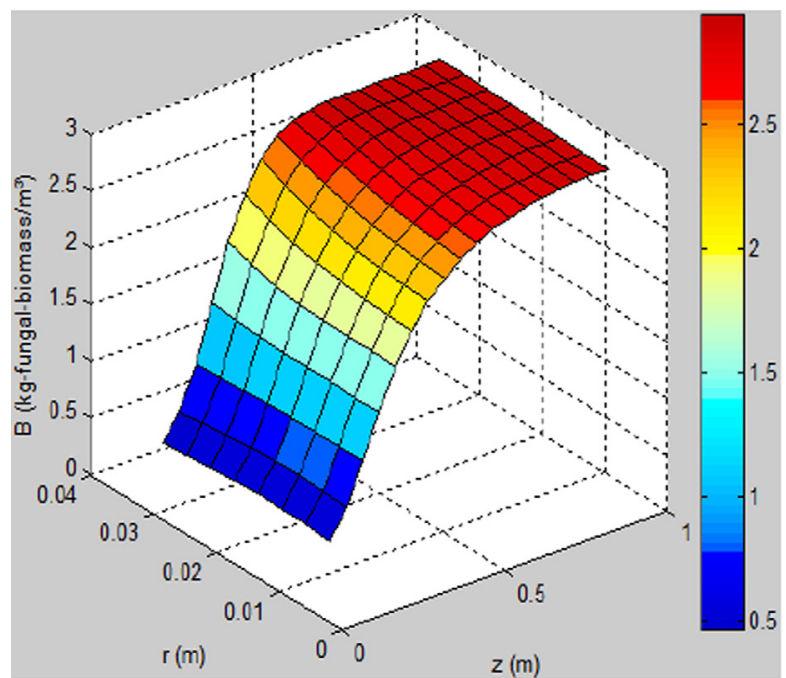

(e)

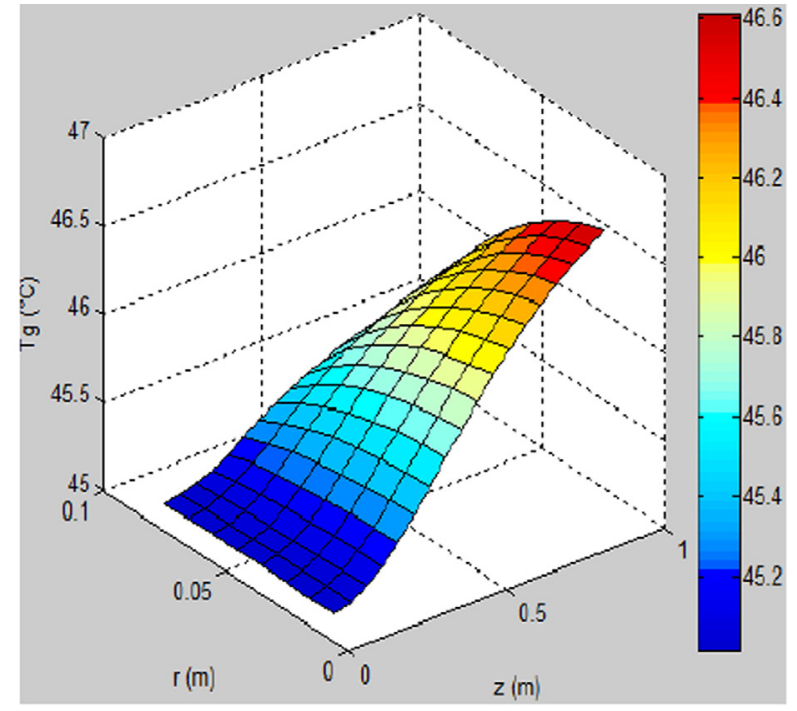

(b)

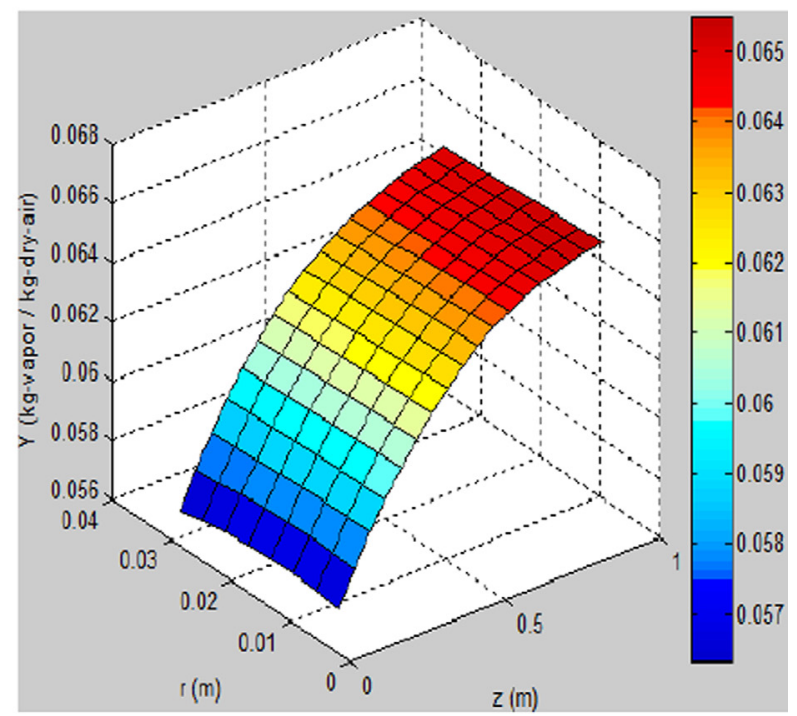

(d)

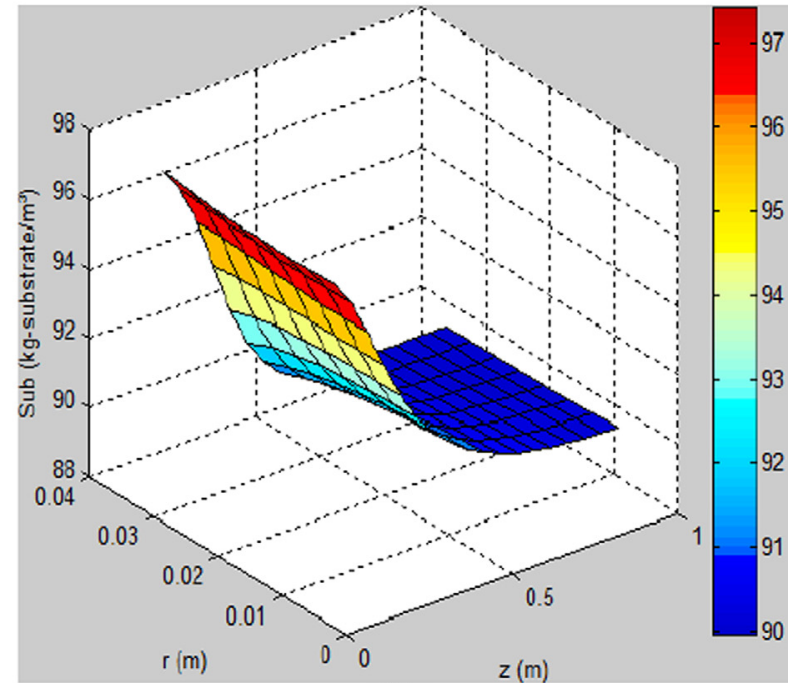

(f)

Fig. 2. Predicted spatial profiles of: (a) $T_{s}$; (b) $T_{g}(t=48 \mathrm{~h})$; (c) $X$; (d) $Y$; (e) B; (f) Sub $(t=96 \mathrm{~h})$. 
The first term on the right-hand side describes the convective heat transfer in the gas-solid interface. The second term represents the amount of energy associated to the water evaporation flux in the gas-solid interface. The third term addresses the production of metabolic heat during the fungal growth. This term is similar to the one representing the production of metabolic water in Eq. (2). Then the product rule was used also within the metabolic heat generation term.

The last two terms represent the heat conduction through the solid-phase in axial and radial directions, respectively. Since the solid-phase remains static along the fermentation, the heat and mass transfer effective coefficients for the solid-phase were assumed not to depend on the air flow. Hence, the water dispersion parameters $D_{s, z}$ and $D_{s, r}$ for axial and radial diffusivities of water on the solid-phase were fitted as $D_{s, z}=D_{s, r}=D_{s}$. $D_{s}$ was experimentally obtained by thermo-gravimetric analysis (TGA) [49,54] and the medium was assumed isotropic. Also for the heat dispersion parameter, the solid matrix was assumed to be isotropic and the thermal conductivity of the solid-phase $\left(\lambda_{s}\right)$ was fitted from experimental data for stagnant effective thermal conductivity $\left(\lambda_{0}\right)[50]$ and assumed constant and equal for axial and radial directions.

\subsection{Numerical solution}

To solve the system of partial differential equations, the spatial derivatives were approximated by finite volumes using equal-sized elements, with spatial step-sizes chosen by the user. This approximation resulted in a set of ordinary differential equations, which were simultaneously numerically integrated by ode15s solver in MATLAB ${ }^{\circledR}$ R2012b (MathWorks Inc., Natick, Massachusetts, United States).

The initial conditions $(t=0)$ are the following: $B=B_{0}, b=b_{0}$, $S=S_{0}, \mathrm{Sub}=\mathrm{Sub}_{0}, Y=Y_{0}, X=X_{0}, T_{g}=T_{g 0}, T_{s}=T_{s 0}$. The boundary conditions were assumed to be as follows:

\begin{tabular}{c|ll}
$z=0$ & $Y=Y_{0} ; \quad T_{g}=T_{g 0}$ \\
(inlet) & $\frac{\partial X}{\partial z}=0 ; \quad \frac{\partial T_{s}}{\partial z}=0$
\end{tabular}

$\begin{gathered}z=L \\ \text { (outlet) }\end{gathered} \mid \frac{\partial X}{\partial z}=\frac{\partial Y}{\partial z}=\frac{\partial T_{g}}{\partial z}=\frac{\partial T_{s}}{\partial z}=0$

$$
\begin{aligned}
& r=0 \\
& \text { at central axis) }
\end{aligned} \mid \frac{\partial X}{\partial r}=\frac{\partial Y}{\partial r}=\frac{\partial T_{g}}{\partial r}=\frac{\partial T_{s}}{\partial r}=0
$$

$r=R($ wall $) \mid \begin{aligned} & \frac{\partial Y}{\partial r}=0 ; \quad \frac{\partial X}{\partial r}=0 \\ & -\Lambda_{g, r} \frac{\partial T_{g}}{\partial r}=\alpha_{\text {wall }}\left(T_{g_{R}}-T_{\text {wall }}\right) ; \quad-\lambda_{s} \frac{\partial T_{s}}{\partial r}=\alpha_{\text {wall }}\left(T_{S_{R}}-T_{\text {wall }}\right)\end{aligned}$

where $T_{g R}$ and $T_{S R}$ are the temperatures of gas and solid-phases, respectively, at $r=R$.

\section{Results and discussion}

\subsection{Simulation data for nominal case}

Fig. 2 presents the predicted spatial profiles at $\mathrm{t}=48 \mathrm{~h}$ (halftime of fermentation) for solid $\left(T_{s}\right)$ and gas $\left(T_{g}\right)$ phase temperatures and at $t=96 \mathrm{~h}$ (end-time) for solid $(X)$ and gas $(Y)$ phase moisture contents and biomass $(B)$ and substrate (Sub) concentrations.

Fig. 2a and b display similar spatial temperature profile and quite close temperature values at $t=48 \mathrm{~h}$ (half-time of fermentation) for both $T_{s}$ and $T_{g}$, respectively, indicating that both phases may be considered to be in thermal equilibrium throughout the fermentation. The probable reason for that was the high value of

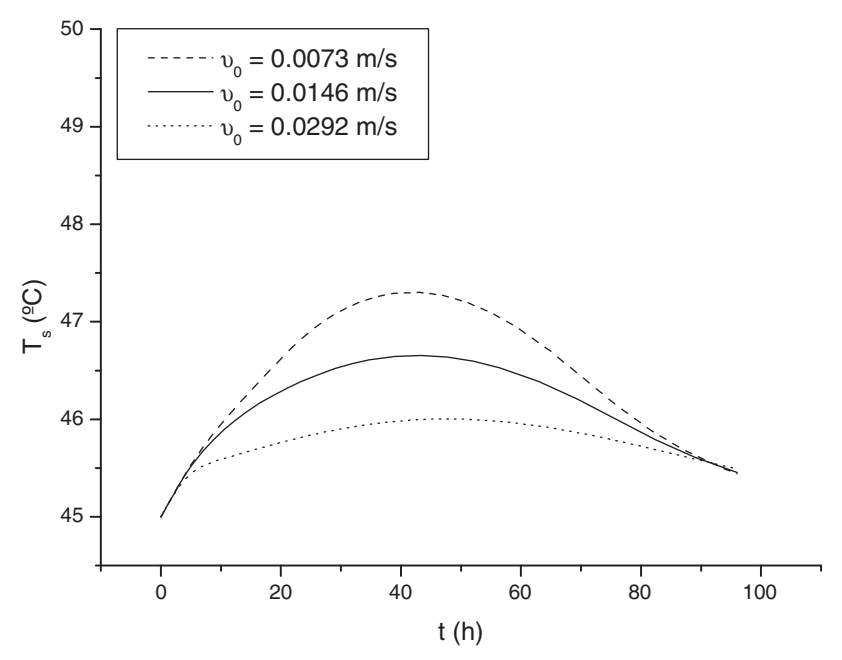

(a)

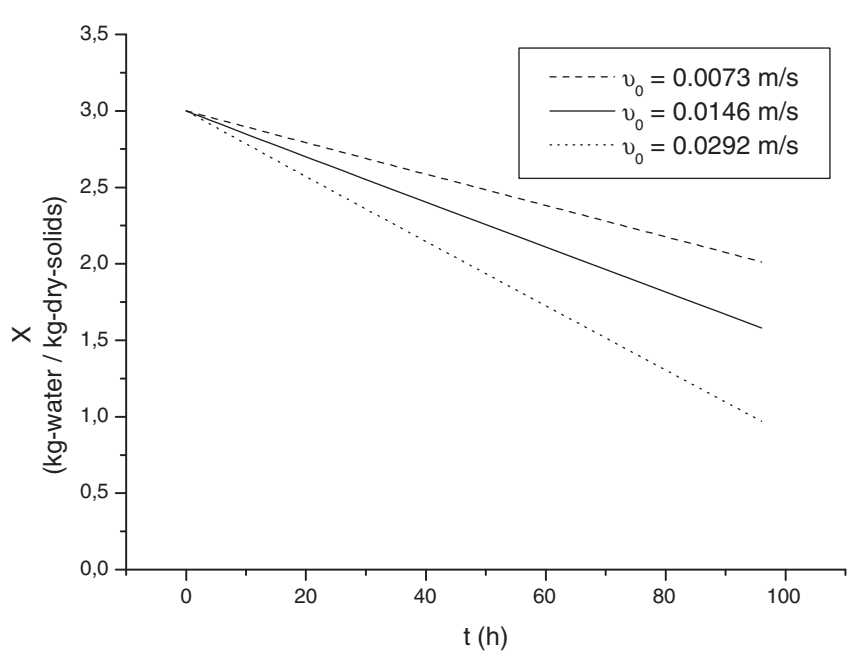

(b)

Fig. 3. Effect of inlet air superficial velocity on solid-phase variables: (a) $T_{S}$ $(z / L=0.925 ; r / R=0.05)$; (b) $X(z \mid L=0.075 ; r / R=0.05)$.

the volumetric interface heat transfer coefficient (ha), since the total transfer area in a volume element was very large (around $2.10^{3} \mathrm{~m}^{-1}$ ). Only very close to the bed inlet, it was possible to observe that $T_{g}$ was kept on $45^{\circ} \mathrm{C}$ (Fig. 2b), while $T_{s}$ dropped a bit under $45^{\circ} \mathrm{C}$ (Fig. 2a), probably due to the intensive water removal from the solid-phase observed in this region (see Fig. 2c). However, the gap between $T_{s}$ and $T_{g}$ were still less than $0.5^{\circ} \mathrm{C}$, hence both temperatures may be considered physically equal within the bed throughout the fermentation, since any thermal sensor wouldn't capture precisely that difference [2]. Therefore, the pseudo-homogeneous approximation usually applied in literature might be considered reasonable also for the process here simulated. Hence, such result suggests that, although the model has to be heterogeneous to represent water transfer from the solid to the gas phase, allowing predictions of moisture content profiles, it may be sufficient to measure only $T_{g}$ in order to represent the temperature of the fermentation system as a whole, overcoming the problem of measuring $T_{s}$ to validate the model.

The highest temperatures were predicted to be reached at the top of the bioreactor around $48 \mathrm{~h}$, as already has been reported 
in literature dealing with homogeneous models [30-34]. Moreover, since the model here proposed is 2-D and the bioreactor is narrow, a noticeable radial temperature profile may be seen, as a consequence of heat removal by the jacket. The maximum values were under $46.5^{\circ} \mathrm{C}$, hence less than $1.5^{\circ} \mathrm{C}$ over the ideal process temperature. If the term of radial conduction is neglected, the model becomes 1-D and then the maximum temperature predicted reaches $48{ }^{\circ} \mathrm{C}$. Such result addresses that jacket plays an important contribution for metabolic heat removal for small-diameter PBB. Hence, overheating shall not be expected in this nominal case, agreeing with previous experimental observations [14,40,55]. A 1-D model would not predict the role of the jacket on heat removal, reinforcing the advantage of using a 2-D model, as proposed in the current paper.

The spatial profiles of $X$ and $Y$ at end-time of fermentation (Fig. 2c and d) follow the spatial $T_{s}$ and $T_{g}$ profiles, respectively, since such variables are directly related. Once $T_{s}$ and $T_{g}$ increased in direction to bed-outlet and central-axis, $X$ and $Y$ increased as well, due to the changing on the saturation moisture content of the air as a function of temperature, giving drying force. Hence, it was possible to see a mild radial profile of $X$ and $Y$, with slightly higher $X$ and $Y$ values predicted close to the bed-wall. Only a 2-D model can show such kind of result. However, nearby bed-inlet, $X$ values were quite low, since the solid phase has undergone fast water removal by end-to-end non-saturated aeration (relative humidity RH 85\%), which is expected to be minimized in case saturated air is supplied to the bioreactor. The severe moisture content reduction of the solid matrix at the bottom of the bioreactor (Fig. 2c) seemed to be much more serious than the overheating in this nominal case. However, $\mathrm{RH} 85 \%$ is unusual for air supply in SSF bioreactors; this value has been chosen for the nominal case in order to make clear the undesired drying effect occurring in PBB for SSF with end-to-end non-saturated aeration. The effect of RH of the inlet air on $T_{S}$ and $X$ throughout the fermentation and consequent effects on fungal growth were further explored in this paper.

As a consequence of the severe solid-phase drying nearby bedinlet, spatial profiles of $B$ and Sub were predicted as well (Fig. 2e and f, respectively), showing steeply and slightly gradients in axial and radial directions, respectively. Biomass growth and substrate consumption were mainly harmed in the region near to the bed inlet. Since the temperature nearby bed-inlet was kept at the optimum value for the microbial growth, the only explanation for biomass growth to be harmed was the intense substrate moisture content reduction, and consequently the lower water activities $\left(a_{w s}\right)$ reached there. It may be suggested that probably some fungal metabolic activities that require a water film to be accomplished might have been affected by $a_{w s}$ reduction.

Grajek [56] studied the growth conditions of one mesophilic (Trichoderma viride) and two thermophilic fungi in SSF (Thermoascus aurantiacus and Sporotrichum thermophile). The author reported that a slight variation around the optimal $a_{w s}$ value for fungal development caused large disturbance in the growth and metabolism of fungi. The results presented by Grajek showed that the admissible $a_{w s}$ variation which assures a normal culture development varies only from 0.005 to 0.01 around the optimum $a_{w s}$ value. Moreover, the same author observed that both the thermophilic strains were more sensitive to $a_{w s}$ changes than the mesophilic fungal, since an appreciable growth rate for the thermophilic organisms was only noticed at very elevated $a_{w s}$ values, nearly 1.0.

Therefore, for the nominal case, the enzyme production in the bottom zone of the bioreactor tends to be lower than in upper regions, a problem already reported in literature even when saturated air was supposed to be supplied to the bioreactor $[14,23,41,55,57,58]$. Notice that, according to Fig. 2e and f, B and Sub will reach maximum values over $30 \mathrm{~cm}$, meaning that about one third of the PBB is underutilized.

\subsection{Simulation data for other set of operational conditions and geometries}

The effects of inlet air superficial velocity $\left(v_{0}\right)$ and moisture content $\left(Y_{0}\right)$ on model predictions of $T_{s}$ and $X$ were evaluated. Fig. 3 displays profiles of $T_{s}$ (nearby bed-outlet) and $X$ (nearby bedinlet) predicted for three levels of $v_{0}$, while Fig. 4 displays the same profiles predicted for three levels of $Y_{0}$ (RHs 85, 95 and $100 \%$ at $\left.45^{\circ} \mathrm{C}\right)$.

The influence of $v_{0}$ on predictions of $T_{s}$ is negligible when using the 2-D model (Fig. 3a). If heat conduction in radial direction is neglected, then $v_{0}$ plays significant effect on $T_{s}$ predictions. This result, only predictable by a $2-\mathrm{D}$ model, suggests that, at such a narrow PBB with non-saturated aeration, the mechanism of heat removal by tube-wall is so intense that it almost overcomes the influence of the convective transport. Hence, it might be proposed that lower air flow rates could be employed in order to minimize substrate drying, as it can be seen in Fig. $3 \mathrm{~b}$.

According to Sangsurasak and Mitchell [31,32], $v_{0}$ typically used in PBB are under $0.1 \mathrm{~m} / \mathrm{s}$. According to Grajek [56], from a technological point of view, the maximum temperature variation considered admissible is such that fungal growth decreases a maximum up to $20 \%$. For that author, a temperature variation estimated as $4{ }^{\circ} \mathrm{C}$ was defined as the maximum accepted for a thermophilic fungal culture. For the current nominal case, with $v_{0}$ as low as $0.004 \mathrm{~m} / \mathrm{s}$, the 2-D model predicted that $T_{s}$ at the top of the bed could reach a maximum of $47.5^{\circ} \mathrm{C}$, which would still not be deleterious for fungal growth and product formation. Hence, no high $v_{0}$ is required in terms of heat removal, since higher air velocities would consume more power for air supplying and also would dry the substrate to unfavorable low moisture levels. Consequently, low $a_{w s}$ would be undergone by the solid matrix, which would affect negatively the fungal growth and impair the enzymes production.

Ghildyal et al. [23] showed experimentally that high $v_{0}$ decreased the peak of temperature by experiments with a fast growing mesophilic microorganism in a PBB $34.5 \mathrm{~cm}$ high and $15 \mathrm{~cm}$ diameter. For their case, when the PBB was aerated with air at $30^{\circ} \mathrm{C}$, the maximum temperature observed at the middle of the column was $52{ }^{\circ} \mathrm{C}$ for $v_{0}=0.0047 \mathrm{~m} / \mathrm{s}$ and $36{ }^{\circ} \mathrm{C}$ for $v_{0}=0.0236 \mathrm{~m} / \mathrm{s}$. However, not only temperature and moisture content shall be considered in SSF analysis, since other needs of the microbe can be affected by the operational conditions. Casciatori et al. [40] have found experimentally that cellulase activities were significantly lower for $v_{0}=0.0073 \mathrm{~m} / \mathrm{s}$ in comparison with $v_{0}=0.0146 \mathrm{~m} / \mathrm{s}$, attributing such phenomenon to oxygen restriction to $M$. thermophila metabolical needs.

Concerning the effect of $v_{0}$ on $X$ nearby bed-inlet (Fig. 3b), considering or not radial water dispersion doesn't matter, since temperatures at lower parts of the PBB were predicted to be kept around $45^{\circ} \mathrm{C}$ either considering or not radial heat conduction. Substrate drying occurred for any $v_{0}$, with drying rate increasing as $v_{0}$ increases. Values of $X$ lower than $2 \mathrm{~kg}$-water $/ \mathrm{kg}$-total-dry-solids lead $a_{w s}$ to values under 0.90, harming fungal growth. For $v_{0}=0.0073 \mathrm{~m} / \mathrm{s}$, solid-phase took longer to reach critical $a_{w s}$ values, but such low $v_{0}$ may represent a restriction of oxygen to microbial needs. Hence, a balance between both phenomena must be done in order to find the most appropriate air flow rate. Therefore, the model can be further improved in order to include gas exchanges (oxygen uptake and carbon dioxide release).

The influence of $Y_{0}$ on predictions of $T_{s}$ is negligible when using the 2-D model (Fig. 4a). If heat conduction in radial direction is neglected, then $Y_{0}$ plays significant effect on $T_{s}$ predictions. This result, again only predictable by a $2-\mathrm{D}$ model that contains an appropriate term of drying (hence properly a heterogeneous model), suggests that, at a narrow jacketed PBB, the mechanism 


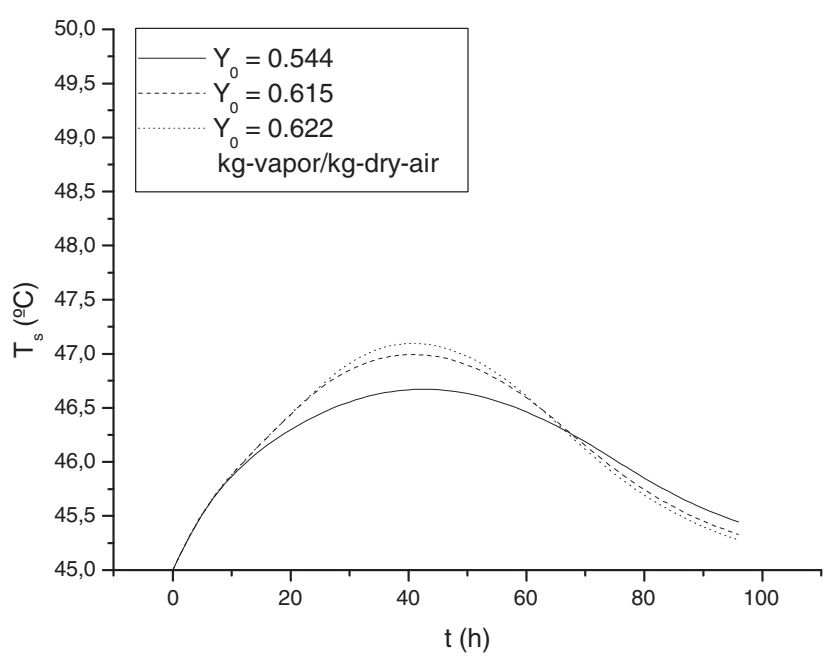

(a)

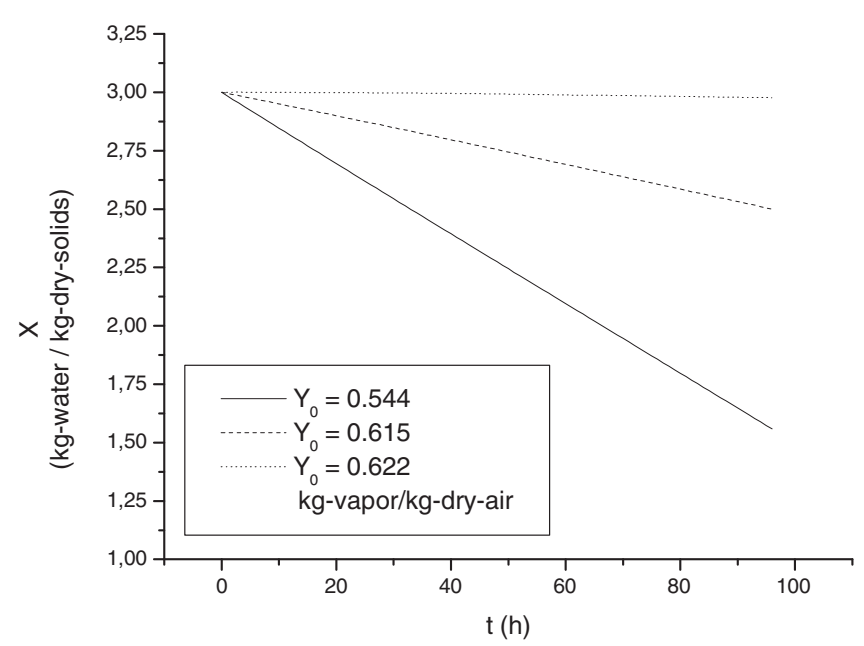

(b)

Fig. 4. Effect of inlet air moisture content on solid-phase variables: (a) $T_{S}$ $(z / L=0.925 ; r / R=0.05)$; (b) $X(z / L=0.075 ; r / R=0.05)$.

of heat removal by tube-wall is so intense that it almost overcomes the influence of the evaporative transport. Hence, it might be proposed that saturated air is supplied to the PBB, in order to minimize substrate drying, as it can be seen in Fig. 4b. Concerning the effect of $Y_{0}$ on $X$ (Fig. 4b), considering or not radial water dispersion doesn't matter, pointing that moisture migration by capillary in radial direction is negligible in comparison with water removal by evaporation for $v_{0}=0.0146 \mathrm{~m} / \mathrm{s}$. Furthermore, $Y_{0}$ can modify the shape of the axial $X$ profile. When non-saturated air is blown, the bottom of the bed dries out quickly; for saturated aeration, the bottom region dries out slower than upper regions of the PBB. Such results agreed with simulations presented by Mitchell et al. [20] employing the model proposed by Von Meien and Mitchell [37], as well as with experimental results reported by Gowthaman et al. [41] and Ghildyal et al. [23]. For saturated aeration and $v_{0}=0.0141 \mathrm{~m} / \mathrm{s}$, Ghildyal et al. [23] found experimentally that $X$ increased over time or stayed constant nearby bed inlet and decreased along time from mid-height and above.

Fig. $5 \mathrm{a}$ and b shows B predicted at $z / L=0.075,0.525$ and 0.925 at $r / R=0.05$ for aeration with $\mathrm{RH} 85$ and $95 \%$, respectively. Since nearby bed-inlet $(z / L=0.075) T_{s}$ remained close the ideal process temperature, one can conclude that fungal growth were strongly limited (Fig. 5a) by low $a_{w s}$ reached at that region for aeration with RH 85\%. On the other hand, for aeration with $\mathrm{RH} 95 \%$, fungal growth was homogeneous (Fig. 5b) along the length of the PBB, agreeing with experimental results reported by Grajek [56]. On the above, it was clear that, for the fermentation system used in this case-study, the porous medium drying is more deleterious to the microbial growth than overheating. However, overheating may become a critical situation when the bioreactor is scaled-up by diameter increasing.

Fig. 6a-d present radial $T_{s}$ profiles at $t=48 \mathrm{~h}$ for PBB internal diameters $7.62,15,20$ and $50 \mathrm{~cm}$. For any diameter, $v_{0}$ is constant; this means airflow rate increased proportionally to the increase of the cross-section area. Except at $z / L=0.075$ (nearby bed inlet), where the influence of the inlet air temperature kept $T_{s}$ restrained, the effect of bed diameter was pronounced. For the narrowest-PBB, heat removal by the jacket is effective, resulting radial $T_{s}$ profile almost flat (Fig. 6a). For 15 and $20 \mathrm{~cm}$ diameters, radial heat removal becomes less effective and a non-negligible radial temperature gradient is observed (Fig. $6 \mathrm{~b}$ and c). For the largest-PBB, radial heat removal becomes negligible (Fig. 6d) and $T_{s}$ is influenced by wall-temperature only at the close vicinity of the wall $(r / R>0.75)$.

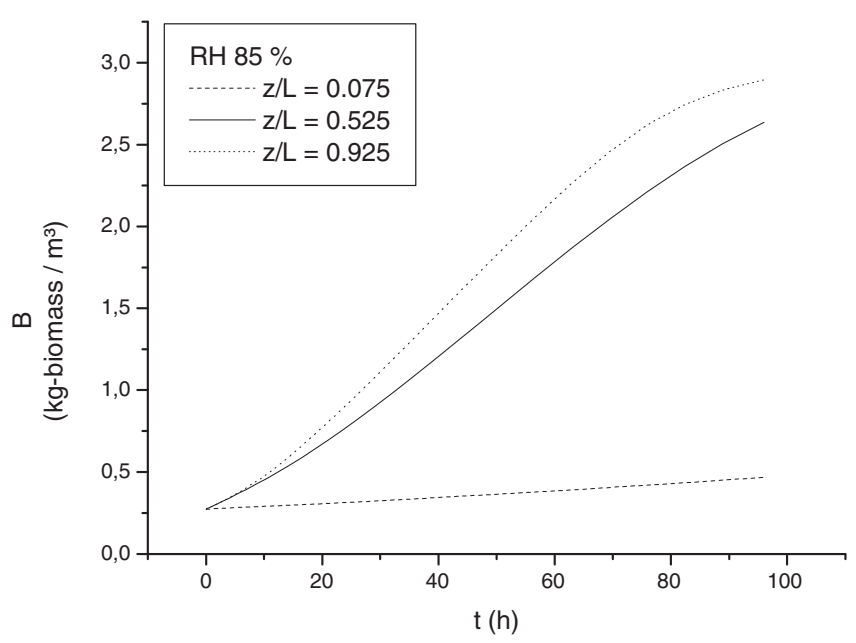

(a)

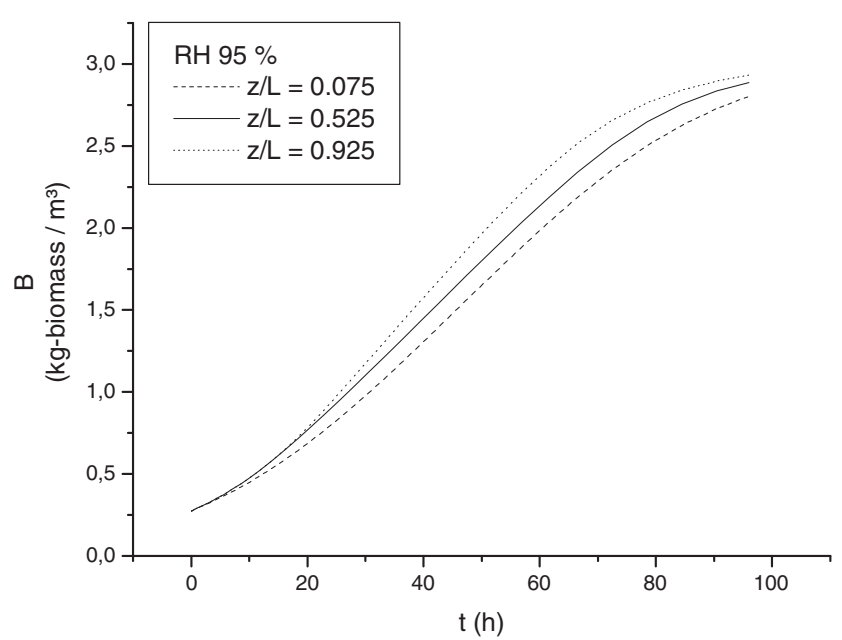

(b)

Fig. 5. Biomass concentration time-profiles: (a) for inlet air with RH 85\%; (b) for inlet air with RH $95 \%$. 
Sangsurasak and Mitchell [31,32] evaluated the effect of $L / D$ ratios on the temperature predictions using a pseudohomogeneous 2-D model. They kept constant the total PBB volume, as well as $v_{0}$. When decreasing $L / D$ ratio, thermal gradients became negligible and microbial growth was optimum. However, it must be considered that those authors varied $L / D$ keeping the total PBB volume as constant, supposing that increases in length produces the same effect than increases in diameter. Increasing the length and keeping the diameter constant means a reduction in the volumetric aeration rate, affecting convective heat transfer, an effect not considered by Sangsurasak and Mitchell. Therefore, the selection of the appropriate bed dimensions will depend on the ratio between the cross section surface area by the total volume. It must also be taken into account the possibility of fluidization due to the high air flow rate and deleterious effects of high air velocity on the microbial physiology. Another aspect to be considered is the bed compaction for long columns.

Some additional calculations were performed in order to evaluate the influence of transport properties of the solid-phase $\left(K_{s}\right.$ and $D_{s}$ ) on the 2-D model time-profiles predictions for solid-phase temperature and moisture content. The target of these calculations was to reinforce the important role that conduction and dispersion terms in the equations, combined with realistic parameters values, play on model predictions. Such terms are one of the main novel-

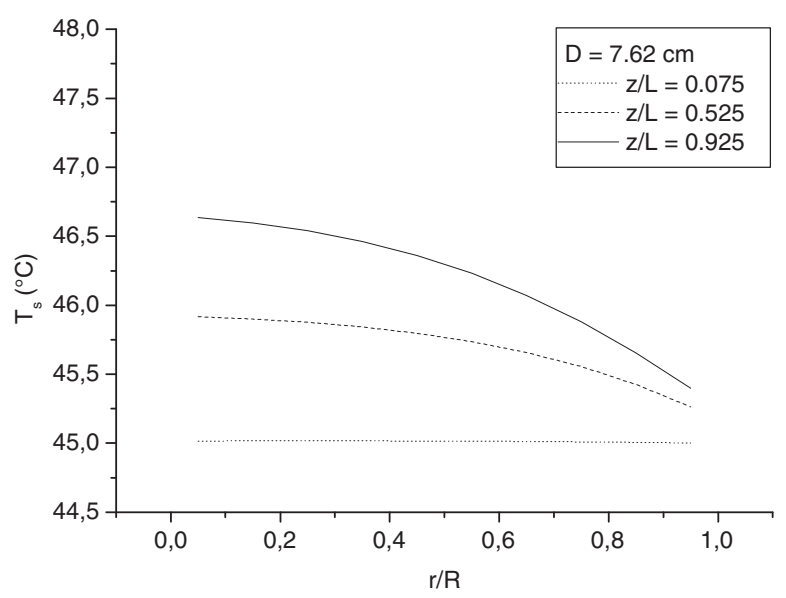

(a)

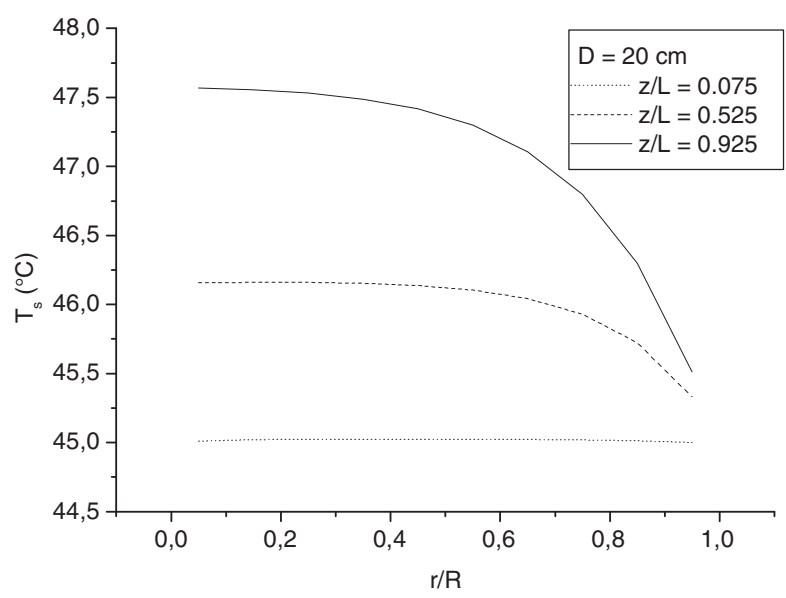

(c) ties of the 2-D heterogeneous model here proposed. The temperature of the solid phase was predicted close to bed-outlet $(z / L=0.925)$, and the moisture content close to bed-inlet $(z / L=0.075)$, keeping constant the air flow rate $(240 \mathrm{~L} / \mathrm{h})$, the inlet air relative humidity (85\%), the bioreactor diameter $(76.2 \mathrm{~mm})$ and the radial position $(r / R=0.05)$.

Although convection and evaporation are known to be the dominant heat transfer mechanisms, $K_{s}$ values influenced temperature time-profiles predicted by 2-D model (data not shown), being higher the maximum temperature reached for lower values of $K_{s}$. On the other hand, neglecting radial heat conduction, there was no discernible difference in the predicted $T_{s}$ profiles when running simulations for a wide range of $K_{s}$ values (data not shown), confirming the despicable influence of conduction term in the 1-D model. Since the axial conduction mechanism has been considered negligible in classical literature of heat transfer in packed-beds [36,59], the effect of $K_{s}$ on $T_{s}$ predicted by 2-D model has to be attributed to the high radial heat dissipation. Hence, for narrow bioreactors, the radial heat conduction term must be considered, giving as a result the need of a 2-D model.

Although convective drying is the most important phenomena affecting solid-phase moisture content profiles, $D_{s}$ values showed to have little, even though noticeable, influence on the $X$ timeprofiles predicted by 2-D model (data not shown). Until half-time

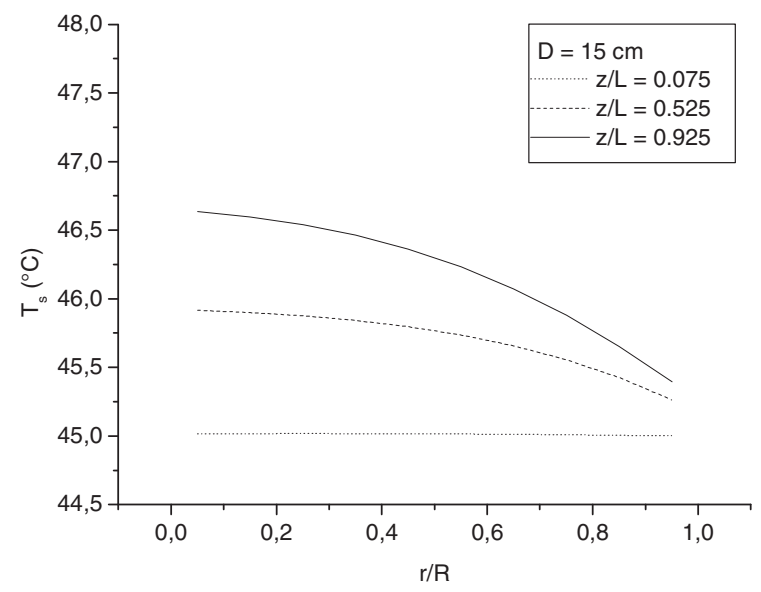

(b)

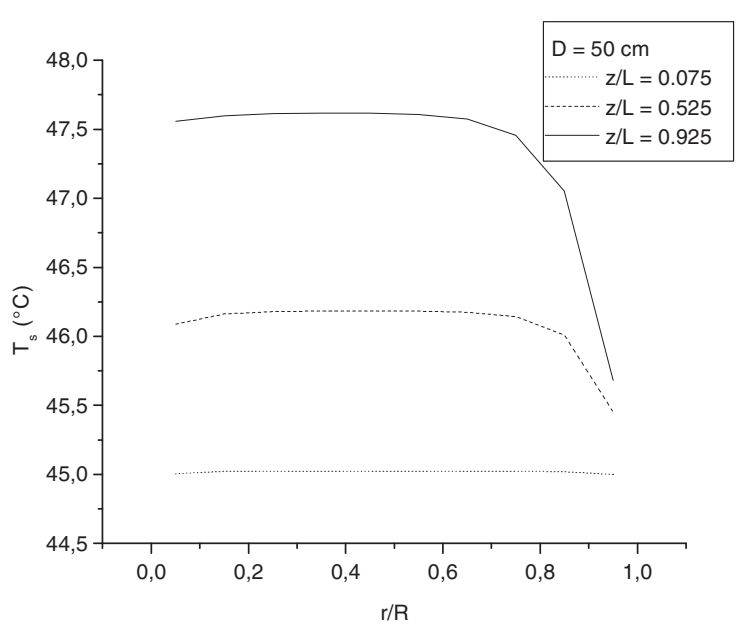

(d)

Fig. 6. Radial-profiles of $T_{s}(t=48 \mathrm{~h}$ ) for PBB diameters: (a) 7.62; (b) 15; (c) 20; (d) $50 \mathrm{~cm}$. 


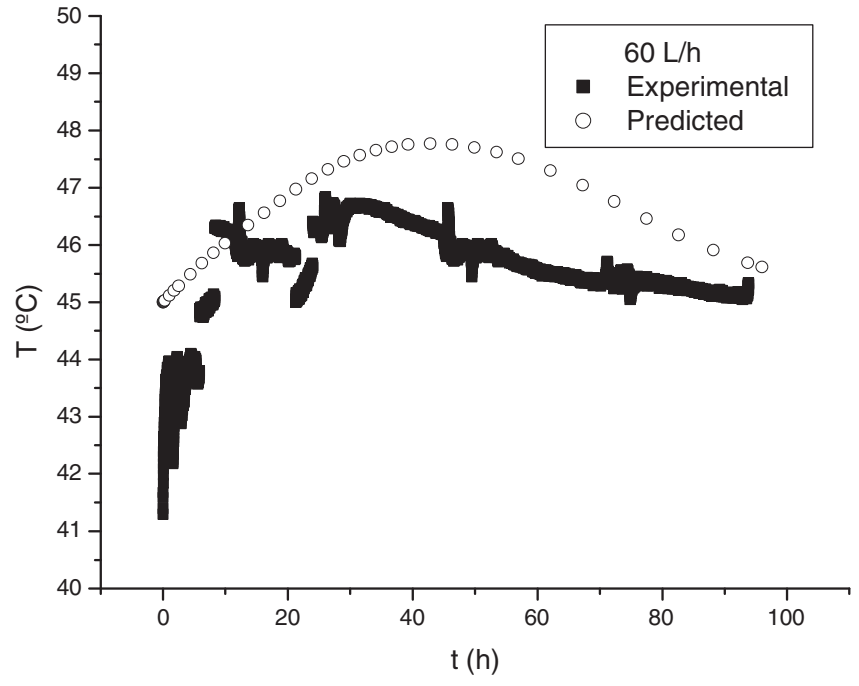

(a)

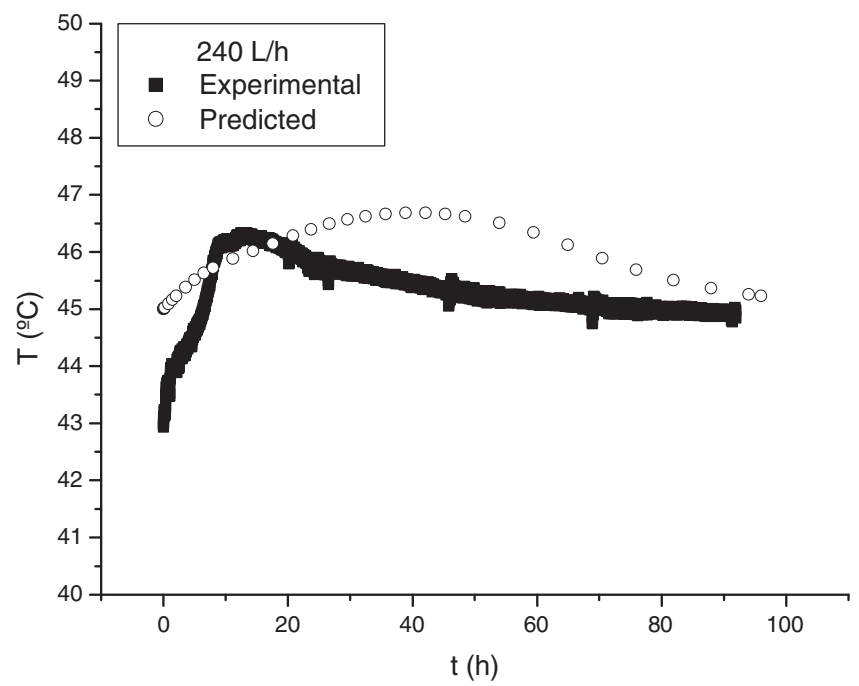

(b)

Fig. 7. Experimental and predicted time-profiles of $T_{s}(z / L=0.925 ; r / R=0.05)$ : (a) air flow rate $60 \mathrm{~L} / \mathrm{h}$; (b) air flow rate $240 \mathrm{~L} / \mathrm{h}$.

of fermentation, no influence of $D_{s}$ on $X$ was observed; however, after around $40 \mathrm{~h}$, an increase in $D_{s}$ produced a decrease in $X$ predicted by the 2-D model, while no influence was observed when radial water dispersion was neglected (data not shown). Therefore, such effect of $D_{s}$ on solid-phase moisture content predicted by 2-D model should be associated to the radial temperature profile rather than to the axial one. Probably such association may be explained by Soret effect, defined as the water migration induced by temperature gradient [60]. On the other hand, predicted solid-phase temperature was not sensitive to $D_{s}$ (data not shown), suggesting that Dufour effect, defined as heat transfer induced by moisture gradient [60], would be in fact negligible for the case-study system.

\subsection{Verification of simulated results}

Experimental data for verification of the simulated results were obtained from Casciatori [29]. Temperature was monitored along

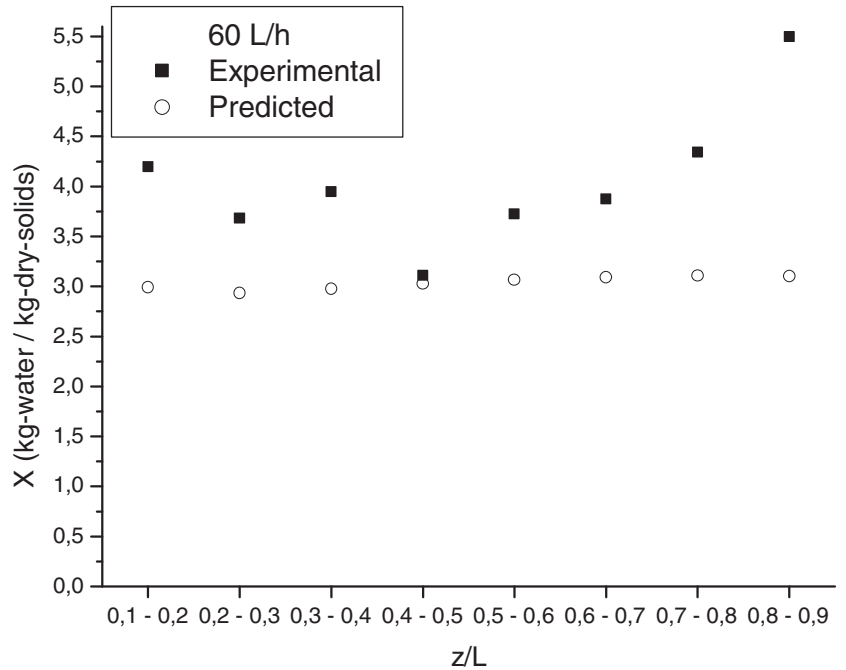

(a)

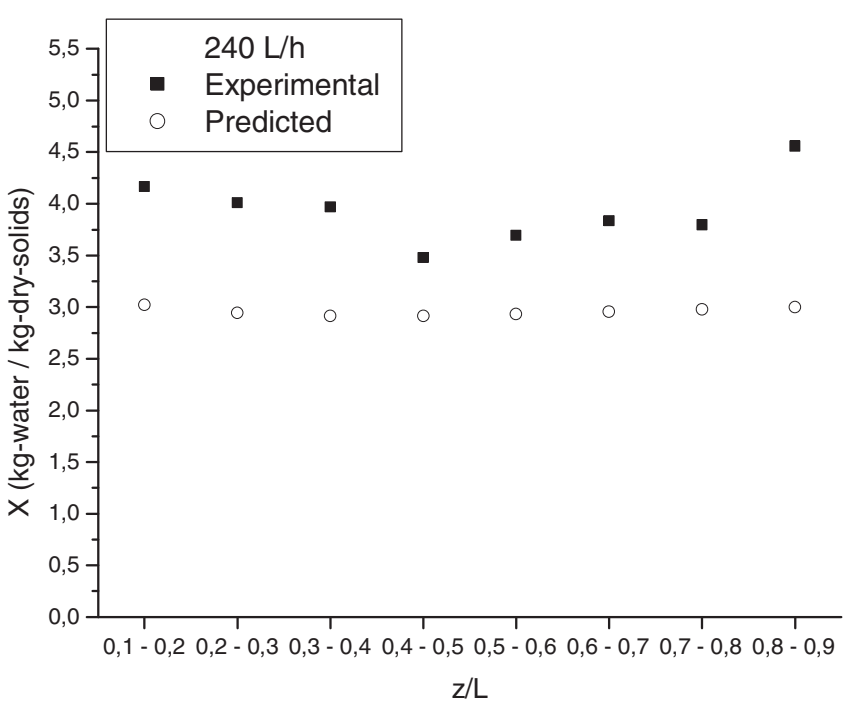

(b)

Fig. 8. Experimental and predicted $X$ along $z / L$ at end-time of fermentation: (a) air flow rate $60 \mathrm{~L} / \mathrm{h}$; (b) air flow rate $240 \mathrm{~L} / \mathrm{h}$.

the process and moisture content of the fermented material was measured along PBB length at the end of the fermentation. Fig. 7a and b display $T_{s}$ time-profiles nearby bed-outlet $(z / L=$ 0.925 and $r / R=0.05$ ) for air flow rates 60 and $240 \mathrm{~L} / \mathrm{h}$ $\left(v_{0}=0.0037\right.$ and $0.0146 \mathrm{~m} / \mathrm{s}$, respectively). For both cases, a good agreement was observed, even though simulated profile for $240 \mathrm{~L} / \mathrm{h}$ is smoother than for $60 \mathrm{~L} / \mathrm{h}$. If one considers that the differences among measured and simulated temperatures were around $1{ }^{\circ} \mathrm{C}$, the model predictions can be considered enough good for engineering purposes.

Fig. 8a and b display final moisture content of the fermented material along the PBB length experimentally obtained by Casciatori [29] and simulated with air flow rates 60 and $240 \mathrm{~L} / \mathrm{h}$, respectively. A reasonable agreement between predicted and experimental axial-profiles of final moisture contents have been observed, mainly within the lower part of the PBB. An explanation for such result is, since it is difficult to control experimentally the relative humidity of the inlet air, $Y_{0}$ is not surely known, leading to some discrepancies between predicted and experimental results. 
Moreover, the model is not able to predict that water vapor may condensate at upper parts of the PBB while the air flows towards bed-outlet, but such phenomenon is known to occur experimentally [14]. Such condensation would lead to an increasing of $X$ at upper regions of the PBB, which seems to have happened.

\section{Conclusions and outlook}

The current work presented a two-phase and two-dimensional model describing heat and water transfer in a packed-bed bioreactor (PBB) for solid-state fermentation (SSF), including most of the transport mechanisms possible to occur. Simulations were carried out using realistic physical, microbial and transport properties. The model was applied to simulate a SSF process using the newly isolated thermophilic fungus $M$. thermophila I-1D3b cultivated in a mixture of sugarcane bagasse and wheat bran $(7: 3 \mathrm{w} / \mathrm{w})$. According to simulations, heat removal by wall plays important role at thermal conditions in narrow PBBs. Superficial velocity $\left(v_{0}\right)$ and moisture content $\left(Y_{0}\right)$ of the inlet air influence temperature rising mainly when wall-cooling is not taken into account. The higher $v_{0}$ and the lower $Y_{0}$, the lower maximum temperature reached at bed-outlet and the lower minimum substrate moisture content reached at bed-inlet. For nominal case, overheating was less troublesome than drying; fungal growth was predicted to be harmed nearby air inlet. On the above, the model proposed enables to predict bioreactor performance for several operational conditions and geometries, therefore the model may be used in further studies as a powerful tool to guide design and scale-up of aerated PBB for SSF.

\section{Acknowledgments}

The authors gratefully acknowledge the funding of this work by the Coordination for the Improvement of Higher Education Personnel (CAPES), by the Fundação de Amparo à Pesquisa do Estado de São Paulo (FAPESP) (Grants \#2011/07453-5, \#2012/13939-0 and \#2014/25183-3) and by the German Federal Ministry of Science and Education (BMBF) as part of the InnoProfile-Transfer project NaWiTec (Grant \#03IPT701X).

\section{Appendix A. Constitutive Relations}

\section{A.1. Fungal growth and specific growth rate}

Correlations describing the specific growth rate $(\mu)$ dependence on temperature $\left(T_{s}\right)$ and water activity $\left(a_{w s}\right)$ of the solid-phase were obtained in literature $[30,37,43,44]$.

The increase of fungal biomass $(b)$ was assumed to follow the logistic equation, commonly used to express the microbial growth in SSF [61]:

$\frac{d b}{d t}=\mu b\left(1-\frac{b}{b_{\max }}\right)$

Relative specific growth rates $\mu_{T}$ (fractional specific growth rate depending on $T_{s}$ ) and $\mu_{W}$ (depending on $a_{w s}$ ) were defined as fractions of the specific growth rate when all conditions are optimal for growth $\left(\mu_{\text {opt }}\right)$, as already assumed by Von Meien and Mitchell [37].

For the water activity ( $a_{w s}$ ) dependence, $\mu_{W}$ was given by an empirical fit to experimental data of Glenn and Rogers [43] for Rhizopus oligosporus:

$\mu_{W}=\exp \left(D_{1} a_{w s}^{3}+D_{2} a_{w s}^{2}+D_{3} a_{w s}+D_{4}\right)$

For $T_{s}$ dependence, $\mu_{T}$ was given by an empirical fit based on Arrhenius-type equation proposed by Saucedo-Castañeda et al. [30] for Aspergillus niger:
$\mu_{T}=\frac{1}{\mu_{\text {opt }}} \frac{\mathrm{A} \exp \left(\frac{-E_{A 1}}{R\left[T_{s}+273\right]}\right)}{1+\mathrm{B} \exp \left(\frac{-E_{A 2}}{R\left[T_{s}+273\right]}\right)}$

The actual specific growth rate was then calculated from the geometric average of the two relative growth rates, as proposed by Sargantanis et al. [44]:

$\mu=\mu$ opt $\sqrt{\mu_{W} \mu_{T}}$

\section{A.2. Balance for total dry solids}

The dry solids concentration $(S)$, which includes both substrate (Sub) and biomass $(B)$ concentrations, is time dependent due to both the consumption of substrate for microbial growth and the production of new biomass as follows:

$\frac{\partial S}{\partial t}=R_{S} \frac{\partial B}{\partial t}=R_{S} \frac{\partial(S . b)}{\partial t}$

\section{A.3. Gas phase moisture content}

The water vapor saturation of the gas-phase was calculated on the basis of the saturation pressure of water vapor at the actual air temperature:

$Y^{*}=\frac{0.62413 P_{w}^{*}}{P-P_{w}^{*}}$

where $Y^{*}$ is the specific saturation moisture content of the air, $P$ is the atmospheric pressure of the moist air and $P_{w}{ }^{*}$ is the saturation pressure of water vapor, calculated by the Antoine equation as a function of the actual air temperature $T_{g}$ [46].

The water activity of the gas-phase $\left(a_{w g}\right)$ at the current $T_{g}$, equivalent to the air relative humidity $(\mathrm{RH})$, was calculated as follows:

$a_{w g}=\frac{Y P}{P_{w}^{*}(Y+0.62413)}$

\section{A.4. Sorption isotherm for the solid-phase}

Considering the larger proportion of SCB in the composition of the substrate, it has been assumed that the sorption isotherm of the substrate is well-represented by the SCB sorption isotherm. According to Casciatori et al. [62], the Oswin [63] equation can be used to describe the SCB isotherm as a function of $a_{w g}$ :

$X^{*}=0.052\left(\frac{a_{w g}}{1-a_{w g}}\right)^{0.409}$

A.5. Heat and mass transport parameters for the gas and for the solidphase

The heat and mass transfer effective coefficients for the gasphase were assumed to depend on the air flow in axial direction and on the structural properties of the bed. The estimated parameters were the axial and radial effective dispersion coefficients for mass (respectively $D_{g, z}$ and $D_{g, r}$ ) and heat (respectively $\lambda_{g, z}$ and $\Lambda_{g, r}$ ) transfers and the wall-to-fluid heat transfer coefficient $\left(\alpha_{\text {wall }}\right)$. The following simplified correlations were used to evaluate the dispersion coefficients $[51,52,64]$ :

$D_{g, z}=\left[1-\left(1-\varepsilon_{0}\right)^{1 / 2}\right] D_{g, m}+\frac{\operatorname{Re}_{p}}{2} v$ 
$D_{g, r}=\left[1-\left(1-\varepsilon_{0}\right)^{1 / 2}\right] D_{g, m}+\frac{\operatorname{Re}_{p}}{8} v$

$\lambda_{g, z}=\left[1-\left(1-\varepsilon_{0}\right)^{1 / 2}\right] \lambda_{g, m}+\frac{\operatorname{Re}_{p}}{2} v$

$\Lambda_{g, r}=\left[1-\left(1-\varepsilon_{0}\right)^{1 / 2}\right] \lambda_{g, m}+\frac{\operatorname{Re}_{p}}{8} v$

where $\operatorname{Re}_{p}=\frac{v_{0} d_{\text {part }}}{v_{a}}$.

The wall-to-fluid heat transfer coefficient $\left(\alpha_{\text {wall }}\right)$ was estimated by using Li and Finlayson [48] correlation:

$\mathrm{Nu}_{\text {wall }}=\frac{\alpha_{\text {wall }} d_{\text {part }}}{\lambda_{g, m}}=0.17 \mathrm{Re}_{p}^{0.79}$

where $\mathrm{Nu}_{\text {wall }}$ is the Nusselt number at the wall.

\section{A.6. Interface gas-solid heat and mass transfer coefficients}

In the present work, the interface gas-solid heat and mass transfer coefficients were calculated from classical correlations for Nusselt ( $\mathrm{Nu}$ ) and Sherwood (Sh) numbers from literature. For the nominal case, it has been supposed that $70 \%$ of the particles had air in cross-flow and 30\% in parallel flow. Hence, Nusselt numbers were calculated for cylinders in cross-flow $\left(\mathrm{Nu}_{\mathrm{cf}}\right)$ by Churchill and Bernstein [65] correlation:

$\mathrm{Nu}_{c f}=0.3+\frac{0.62 \operatorname{Re}_{p}^{1 / 2} \operatorname{Pr}^{1 / 3}}{\left[1+(0.4 / \operatorname{Pr})^{2 / 3}\right]^{1 / 4}}\left[1+\left(\frac{\operatorname{Re}_{p}}{282,000}\right)^{5 / 8}\right]^{4 / 5}$

and in parallel flow $\left(\mathrm{Nu}_{p f}\right)$ by correlation for flat-plate [65]:

$\mathrm{Nu}_{p f}=0.664 \operatorname{Re}_{f p}^{0.5} \operatorname{Pr}^{1 / 3}$

Afterwards, a balanced Nusselt number $\left(\mathrm{Nu}_{w}\right)$ was obtained. Based on analogy between heat and mass transfer, Sherwood number was assumed to be numerically equal to Nusselt number. Therefore, the interface gas-solid heat transfer coefficient $(h)$ was obtained from the balanced Nusselt number and the interface gas-solid water transfer coefficient $(\beta)$ from the balanced Sherwood number.

Both interface gas-solid heat $(h)$ and mass $(\beta)$ transfer coefficients have to be normalized by the ratio between the total transfer area $\left(A_{T T}\right)$ in the bioreactor and the total volume $\left(V_{B R}\right)$ of the bioreactor, $a=A_{T T} / V_{B R}$, in order to comprise the interface transfer throughout the whole bed. Since $\varepsilon_{0}$ is known, the calculation of $a=A_{T T} / V_{B R}$ was made for one slice of the bed by the following relation:

$a=\frac{A_{T T}}{V_{B R}}=\left(1-\varepsilon_{0}\right) \frac{4}{d_{\text {part }}}$

which is valid for the full bioreactor.

\section{Appendix B. Supplementary data}

Supplementary data associated with this article can be found, in the online version, at http://dx.doi.org/10.1016/j.cej.2015.10.108.

\section{References}

[1] A.G. Dixon, The length effect on packed bed effective heat transfer parameters, Chem. Eng. J. 31 (1985) 163-173.

[2] J.C. Thoméo, C.O. Rouiller, J.T. Freire, Experimental analysis of heat transfer in packed beds with air flow, Ind. Eng. Chem. Res. 43 (2004) 4140-4148.

[3] D. Wen, Y. Ding, Heat transfer of gas flow through a packed bed, Chem. Eng. Sci. 61 (2006) 3532-3542.

[4] K.S.M.S. Raghavarao, T.V. Ranganathan, N.G. Karanth, Some engineering aspects of solid-state fermentation, Biochem. Eng. J. 13 (2003) 127-135.
[5] Y.S.P. Rahardjo, J. Tramper, A. Rinzema, Modeling conversion and transport phenomena in solid-state fermentation: a review and perspectives, Biotechnol. Adv. 24 (2006) 161-179.

[6] D. Madamwar, S. Patel, H. Parikh, Solid state fermentation for cellulase and $\beta$ glucosidase production by Aspergillus niger, J. Ferment. Bioeng. 67 (1989) 424426.

[7] S. Couri, S.C. Terzi, G.A.S. Pinto, S.P. Freitas, A.C.A. Costa, Hydrolytic enzyme production in solid-state fermentation by Aspergillus niger 3T5B8, Process Biochem. 36 (2000) 255-261.

[8] E. Kalogeris, P. Christakopoulos, P. Katapodis, A. Alexiou, S. Vlachou, D. Kekos, B.J. Macris, Production and characterization of cellulolytic enzymes from the thermophilic fungus Thermoascus aurantiacus under solid state cultivation of agricultural wastes, Process Biochem. 38 (2003) 1099-1104.

[9] R. da Silva, E.S. Lago, C.W. Merheb, M.M. Macchione, Y.K. Park, Production of xylanase and CMCase on solid state fermentation in different residues by Thermoascus aurantiacus Miehe, Braz. J. Microbiol. 36 (2005) 235-241.

[10] A.K. Badhan, B.S. Chadha, J. Kaur, H.S. Saini, M.K. Bhat, Production of multiple xylanilytic and cellulolytic enzymes by thermophilic fungus Myceliophthora sp. IMI 387099, Bioresour. Technol. 98 (2007) 504-510.

[11] M. Chandra, A. Kalra, P.K. Sharma, R.S. Sangwan, Cellulase production by six Trichoderma spp. fermented on medicinal plant processings, J. Ind. Microbiol. Biotechnol. 36 (2009) 605-609.

[12] R.K. Sukumaran, R.R. Singhania, G.M. Mathew, A. Pandey, Cellulase production using biomass feed stock and its application in lignocelluloses saccharification for bio-ethanol production, Renew. Energy 34 (2009) 421-424.

[13] K. Brijwani, H.S. Oberoi, P.V. Vadlani, Production of a cellulolytic enzyme system in mixed-culture solid-state fermentation of soybean hulls supplemented with wheat bran, Process Biochem. 45 (2010) $120-128$.

[14] A.I. Zanelato, V.M. Shiota, E. Gomes, R. da Silva, J.C. Thoméo, Endoglucanase production with the newly isolated Myceliophthora sp. I-1D3b in a packed bed solid state fermentor, Braz. J. Microbiol. 43 (2012) 1536-1544.

[15] A. Pandey, Solid-state fermentation, Biochem. Eng. J. 13 (2003) 81-84.

[16] K. Iwashita, Recent studies of protein secretion by filamentous fungi, J. Biosci. Bioeng. 94 (2002) 530-535.

[17] G.D. Haki, S.K. Rakshit, Developments in industrially important thermostable enzymes: a review, Bioresour. Technol. 89 (2003) 17-34.

[18] J. Gao, H. Weng, D. Zhu, M. Yuan, F. Guan, Y. Xi, Production and characterization of cellulolytic enzymes from the thermoacidophilic fungal Aspergillus terreus M11 under solid-state cultivation of corn stover, Bioresour. Technol. 99 (2008) 7623-7629.

[19] A.L. Grigorevski-Lima, F.N.M. da Vinha, D.T. Souza, A.S.R. Bispo, E.P.S. Bon, R.R. R. Coelho, R.P. Nascimento, Aspergillums fumigatus thermophilic and acidophilic endoglucanases, Appl. Biochem. Biotechnol. 155 (2009) 321-329.

[20] D.A. Mitchell, N. Krieger, M. Berovic, Solid-state Fermentation Bioreactors: Fundamentals, Design and Operation, Springer-Verlag, Berlin, 2006.

[21] S.R. Couto, I. Rivela, A. Sanromán, Design of different bioreactor configurations: application to ligninolytic enzyme production in semi-solid-state cultivation, J. Chem. Technol. Biotechnol. 76 (2001) 78-82.

[22] S.R. Couto, A. Sanromán, Application of solid-state fermentation to food industry: A review, J. Food Eng. 76 (2006) 291-302.

[23] N.P. Ghildyal, M.K. Gowthaman, K.S.M.S. Raghavarao, N.G. Karanth, Interaction of transport resistances with biochemical reaction in packed-bed solid-state fermentors: effect of temperature gradients, Enzyme Microb. Technol. 16 (1994) 253-257

[24] D.A. Mitchell, N. Krieger, D.M. Stuart, A. Pandey, New developments in solidstate fermentation. II. Rational approaches to the design, operation and scale up of bioreactors, Process Biochem. 35 (2000) 1211-1225.

[25] D.A. Mitchell, L.E.N. Cunha, A.V.L. Machado, L.F.L. Luz JR, N. Krieger, A modelbased investigation of potential advantages of multi-layer packed beds in solid-state fermentation, Biochem. Eng. J. 48 (2010) 195-203.

[26] J.H. Crowe, L.M. Crowe, D.W. Deamer, Hydration dependent phase changes in a biological membrane, in: F. Franks, S. Mathias (Eds.), Biophysics of Water, Wiley, Chichester, 1982, pp. 295-299.

[27] P. Gervais, P. Molin, The role of water in solid-state fermentation, Biochem. Eng. J. 13 (2003) 85-101.

[28] D.A. Mitchell, O.F. von Meien, N. Krieger, Recent developments in modeling of solid-state fermentation: heat and mass transfer in bioreactors, Biochem. Eng. J. 13 (2003) 137-147.

[29] F.P. Casciatori, Fungal cellulases production by solid-state fermentation: scaleup of fixed-bed bioreactors (Ph.D. Thesis), PPG-ECA/UNESP, São José do Rio Preto, 2015. In Portuguese.

[30] G. Saucedo-Castañeda, M. Gutiérrez-Rojas, G. Bacquet, M. Raimbault, G. Viniegra-González, Heat transfer simulation in solid substrate fermentation, Biotechnol. Bioeng. 35 (1990) 802-808.

[31] P. Sangsurasak, D.A. Mitchell, The investigation of transient multidimensional heat transfer in solid state fermentation, Chem. Eng. J. 60 (1995) 199-204.

[32] P. Sangsurasak, D.A. Mitchell, Incorporation of death kinetics into a 2-D dynamic heat transfer model for solid state fermentation, J. Chem. Technol. Biotechnol. 64 (1995) 253-260.

[33] P. Sangsurasak, D.A. Mitchell, Validation of a model describing twodimensional heat transfer during solid-state fermentation in packed bed bioreactors, Biotechnol. Bioeng. 60 (1998) 739-749.

[34] M.A. Fanaei, B.M. Vaziri, Modeling of temperature gradients in packed-bed solid-state bioreactors, Chem. Eng. Process. 48 (2009) 446-451. 
[35] M. Gutierrez-Rojas, S.A.A. Hosn, R. Auria, S. Revah, E. Favela-Torres, Heat transfer in citric acid production by solid state fermentation, Process Biochem. 31 (1996) 363-369.

[36] J.C. Thoméo, J.T. Freire, Experimental and modeling aspects of heat transfer in packed beds, in: J.T. Freire, A.M. Silveira, M.C. Ferreira (Eds.), Transport Phenomena on Particulate Systems, (ebook), Bentham Sci. Pub, Oak Park, 2012.

[37] O.F. Von Meien, D.A. Mitchell, A two-phase model for water and heat transfer within an intermittently-mixed solid-state fermentation bioreactor with forced aeration, Biotechnol. Bioeng. 79 (2002) 416-428.

[38] V.K. Srivastava, J. John, Deep bed grain drying modeling, Energy Convers. Manag. 43 (2002) 1689-1708.

[39] M.A.I. Schutyser, W.J. Briels, R.M. Boom, A. Rinzema, Combined discrete particle and continuum model predicting solid-state fermentation in a drum fermenter, Biotechnol. Bioeng. 86 (2004) 405-413.

[40] F.P. Casciatori, P.A. Casciatori, J.C. Thoméo, Cellulase production in packed bed bioreactor by solid-state fermentation. EUBC\&E Proc. (2013a) 1539-1546.

[41] M.K. Gowthaman, K.S.M.S. Raghavarao, N.P. Ghildyal, N.G. Karanth, Gas concentration and temperature gradients in a packed bed solid-state fermentor, Biotechnol. Adv. 11 (1993) 611-620.

[42] F.P. Casciatori, C.L. Laurentino, S.R. Taboga, P.A. Casciatori, J.C. Thoméo, Structural properties of beds packed with agro-industrial solid by-products applicable for solid-state fermentation: experimental data and effects on process performance, Chem. Eng. J. 255 (2014) 214-224.

[43] D.R. Glenn, P.L. Rogers, A solid substrate process for an animal feed product: Studies on fungal strain improvement, Aust. J. Biotech. 2 (1988) 50-57.

[44] J. Sargantanis, M.N. Karim, V.G. Murphy, D. Ryoo, R.P. Tengerdy, Effect of operating conditions on solid substrate fermentation, Biotech. Bioeng. 42 (1993) 149-158.

[45] R.H. Perry, L.R. Benskow, W.E. Beimesch, et al., Perry's Chemical Engineers' Handbook, eighth ed., McGraw-Hill, New York, 2008.

[46] R.C. Reid, J.M. Prausnitz, T.K. Sherwood, Properties of Gases and Liquids, third ed., McGraw-Hill, New York, 1977.

[47] M.G.S. Prieto, Alternatives cogeneration in sugar-ethanol industry: a case study (Ph.D. Thesis), UNICAMP, Campinas, 2003. In Portuguese.

[48] C.H. Li, B.A. Finlayson, Heat transfer in packed beds: a revaluation, Chem. Eng. Sci. 32 (1977) 1055-1066.

[49] F.B. Mendes, A.M.C. Gutierrez, Efeito da umidade nas propriedades físicas e estruturais do bagaço de cana, in: XX Congresso Brasileiro de Engenharia Química Proc., 2014.

[50] F.P. Casciatori, C.L. Laurentino, K.C.M. Lopes, A.G. Souza, J.C. Thoméo, Stagnant effective thermal conductivity of agro-industrial residues for solid state fermentation, Int. J. Food Prop. 16 (2013) 1578-1593.

[51] E. Tsotsas, Heat and mass transfer in packed beds with fluid flow, in: VDI Heat Atlas, Springer Verlag, Berlin, 2010.
[52] E. Tsotsas, Thermal conductivity of packed beds, in: VDI Heat Atlas, Springer Verlag, Berlin, 2010.

[53] A.K. Datta, Porous media approaches to studying simultaneous heat and mass transfer in food processes. I: problem formulations, J. Food Eng. 80 (2007) 80 95.

[54] D. Chen, Y. Zheng, X. Zhu, Determination of effective moisture diffusivity and drying kinetics for poplar sawdust by thermogravimetric analysis under isothermal condition, Bioresour. Technol. 107 (2012) 451-455.

[55] M.A. Umsza-Guez, Production of polyglacturonase in solid state fermentation using the fungus Thermomucor indicae-seudaticae N31 in glass flask scale and in a fixed bed bioreactor (Ph.D. Thesis), PPG-ECA/ UNESP, São José do Rio Preto 2009. In Portuguese.

[56] W. Grajek, Cooling aspects of solid-state cultures of mesophilic and thermophilic fungi, J. Ferment. Technol. 66 (1988) 675-679.

[57] M. Khanahmadi, R. Roostaazad, D.A. Mitchell, M. Miranzadeh, R. Bozorgmehri, A. Safekordi, Bed moisture estimation by monitoring of air stream temperature rise in packed-bed solid-state fermentation, Chem. Eng. Sci. 61 (2006) 56545663.

58] S. Ahlawat, B. Battan, S.S. Dhiman, J. Sharma, R.P. Mandhan, Production of thermostable pectinase and xylanase for their potential application in bleaching of kraft pulp, J. Ind. Microb. Biotech. 34 (2007) 763-770.

59] A.G. Dixon, D.L. Cresswell, W.R. Paterson, Heat Transfer in Packed Beds of Low Tube/Particle Diameter Ratio, in: ACS Symposium Series, Oxford, 1978

[60] K.J. Park, A.P. Ito, J.T.C. Leite, Influência da granulometria, do diâmetro e do comprimento de amostras de grãos triturados de soja na determinação de coeficientes simultâneos de transferência, Ciência e Tecnologia de Alimentos 22 (2002) 136-142.

[61] G. Viccini, D.A. Mitchell, S.D. Boit, J.C. Gern, A.S. da Rosa, R.M. Costa, F.D.H Dalsenter, O.F. von Meien, N. Krieger, Analysis of growth kinetic profiles in solid-state fermentation, Food Technol. Biotechnol. 39 (2001) 271-294.

[62] F.P. Casciatori, C.L. Laurentino, A.I. Zanelato, J.C. Thoméo, Hygroscopic properties of agro-industrial solid by-products applied in solid-state fermentation for cellulase production, Ind. Crops Prod. 64 (2015) 114-123.

[63] C.R. Oswin, The kinetics of package life. III. The isotherm, J Chem. Ind. 65 (1946) 419-421.

64] D. Vortmeyer, E. Haidegger, Discrimination of three approaches to evaluate heat fluxes for wall-cooled fixed bed chemical reactors, Chem. Eng. Sci. 46 (1991) 2651-2660.

[65] S.W. Churchill, M. Bernstein, A correlation equation for forced convection from gases and liquids to a circular cylinder in cross flow, J. Heat Transfer, Trans. ASME 94 (1977) 300-306.

[66] J.H. Lienhard IV, J.H. Lienhard V, A heat transfer textbook, third ed., J.H. Lienhard V, Cambridge, 2000. 